OPEN ACCESS

Edited by:

Haihui Ye,

Xiamen University, China

Reviewed by:

Simon G. Webster,

Bangor University, United Kingdom

Taisen lguchi,

Graduate University for Advanced

Studies (Sokendai), Japan

Piero Giulio Giulianini,

University of Trieste, Italy

*Correspondence:

Chi-Ying Lee

bicylee@cc.ncue.edu.tw

Specialty section:

This article was submitted to Experimental Endocrinology,

a section of the journal

Frontiers in Endocrinology

Received: 01 July 2020

Accepted: 09 September 2020

Published: 01 October 2020

Citation:

Chen $\mathrm{H}-\mathrm{Y}$, Toullec J-Y and Lee C-Y (2020) The Crustacean Hyperglycemic

Hormone Superfamily: Progress

Made in the Past Decade.

Front. Endocrinol. 11:578958.

doi: 10.3389/fendo.2020.578958

\section{The Crustacean Hyperglycemic Hormone Superfamily: Progress Made in the Past Decade}

\author{
Hsiang-Yin Chen ${ }^{1}$, Jean-Yves Toullec ${ }^{2}$ and Chi-Ying Lee ${ }^{3 *}$ \\ ${ }^{1}$ Department of Aquaculture, National Penghu University of Science and Technology, Magong, Taiwan, ${ }^{2}$ Sorbonne \\ Université, Faculté des Sciences, CNRS, UMR 7144, Adaptation et Diversité en Milieu Marin, Station Biologique de Roscoff, \\ Roscoff, France, ${ }^{3}$ Graduate Program of Biotechnology and Department of Biology, National Changhua University of \\ Education, Changhua, Taiwan
}

Early studies recognizing the importance of the decapod eyestalk in the endocrine regulation of crustacean physiology-molting, metabolism, reproduction, osmotic balance, etc. - helped found the field of crustacean endocrinology. Characterization of putative factors in the eyestalk using distinct functional bioassays ultimately led to the discovery of a group of structurally related and functionally diverse neuropeptides, crustacean hyperglycemic hormone $(\mathrm{CHH})$, molt-inhibiting hormone $(\mathrm{MIH})$, gonadinhibiting hormone $(\mathrm{GIH})$ or vitellogenesis-inhibiting hormone $(\mathrm{VIH})$, and mandibular organ-inhibiting hormone $(\mathrm{MOIH})$. These peptides, along with the first insect member (ion transport peptide, ITP), constitute the original arthropod members of the crustacean hyperglycemic hormone $(\mathrm{CHH})$ superfamily. The presence of genes encoding the $\mathrm{CHH}$ superfamily peptides across representative ecdysozoan taxa has been established. The objective of this review is to, aside from providing a general framework, highlight the progress made during the past decade or so. The progress includes the widespread identification of the $\mathrm{CHH}$-superfamily peptides, in particular in non-crustaceans, which has reshaped the phylogenetic profile of the superfamily. Novel functions have been attributed to some of the newly identified members, providing exceptional opportunities for understanding the structure-function relationships of these peptides. Functional studies are challenging, especially for the peptides of crustacean and insect species, where they are widely expressed in various tissues and usually pleiotropic. Progress has been made in deciphering the roles of $\mathrm{CHH}$, ITP, and their alternatively spliced counterparts $(\mathrm{CHH}-\mathrm{L}$, ITP-L) in the regulation of metabolism and ionic/osmotic hemostasis under (eco) physiological, developmental, or pathological contexts, and of $\mathrm{MIH}$ in the stimulation of ovarian maturation, which implicates it as a regulator for coordinating growth (molt) and reproduction. In addition, experimental elucidation of the steric structure and structurefunction relationships have given better understanding of the structural basis of the functional diversification and overlapping among these peptides. Finally, an important finding was the first-ever identification of the receptors for this superfamily of peptides, specifically the receptors for ITPs of the silkworm, which will surely give great impetus to 
the functional study of these peptides for years to come. Studies regarding recent progress are presented and synthesized, and prospective developments remarked upon.

Keywords: crustacean hyperglycemic hormone superfamily, structure diversity and evolution, biological functions, peptide structure, signaling pathway and receptor, Ecdysozoa

\section{INTRODUCTION}

It is generally considered that crustacean endocrinology began in the 1920s when a series of studies were published (1-4) confirming that color changes in crustaceans are under hormonal control, although some earlier observations (5-7) had already revealed evidence of endocrine regulation in molting, coloration, and secondary sex characteristics [(8); see (9) for a detailed historical account]. The following years witnessed significant developments indicating that many other physiological processes are also under hormonal regulation by eyestalk-derived factors. Thus, inferences made mainly through ablation and replacement experiments confirmed the presence in the eyestalk of a wide array of presumptive hormones. Physiological processes suggested to be regulated by the eyestalk hormonal factors included, in addition to migration of chromatophoric and retinal pigments, carbohydrate metabolism, reproduction, molting and growth, osmotic and ionic balance, cardiac activity (10). A number of studies (11-16) helped determine the source of these hormonal substances in the eyestalk, the X-organ-sinus gland (XO-SG) complex. The hormonal factors are stored in the sinus gland $(11,17)$, a neurohemal organ (18), which lies next to a blood sinus (hence the name), into which the hormones are released upon stimulation. The sinus gland is a bulbous cluster of neurosecretory axonal terminals, of which the majority of the axonal input originates from the cell bodies of a cluster of neurosecretory cells (the medulla terminalis X-organ) where the hormones are synthesized [see (18)].

Strikingly, most of the presumptive factors have since been biochemically purified and characterized by bioassays, as functionally defined from the earlier studies. These hormones include a group of sequence-related and functionally diverse neuropeptides-crustacean hyperglycemic hormone $(\mathrm{CHH})$, molt-inhibiting hormone (MIH), gonad-inhibiting hormone $(\mathrm{GIH})$ or vitellogenesis-inhibiting hormone (VIH) (this hormone will be referred to as GIH in this review), and mandibular organ-inhibiting hormone (MOIH) that once constituted the entire $\mathrm{CHH}$ family (19-21). The peptides mainly consist of from 72 to more than 80 amino acids. The most remarkable characteristic is the presence of six particularly well-conserved cysteine residues forming three intra-molecular disulfide bridges, which has been shown to be an invariant signature for this superfamily, as it expands with the addition of new members. CHH from the shore crab Carcinus maenas is the first member peptide to be purified and its full amino acid sequence determined (22). This was followed by $\mathrm{CHH}$ isolated from the lobster Homarus americanus, which, interestingly enough, has both $\mathrm{CHH}$ and $\mathrm{MIH}$ activities (23), C. maenas
MIH (24), CHH from the crayfish Orconectes limosus (19), and $H$. americanus GIH (25). Characterization of the sequences available revealed a new peptide family, with the realization that $\mathrm{MIH}$ and GIH are more similar to each other than each to $\mathrm{CHH}$, in terms of sequence similarity, length, and modifications of the termini ( $\mathrm{MIH}$ and $\mathrm{GIH}$ are free, whereas $\mathrm{CHH}$ is blocked, at both ends) $(19,20)$. MOIH was not characterized until a few years later when two biochemically MOIHs, differing from each other only by one amino acid, were purified and characterized from the crab, Cancer pagurus, with the sequences being more similar to MIHs than to $\mathrm{CHHs}$ (26). In the same year, three peptides from the spider crab Libinia emarginata were characterized and found to have $\mathrm{MOIH}$ as well as hyperglycemic activity (27). A cDNA encoding a $\mathrm{CHH}$ precursor protein demonstrated that the spider crab peptide with $\mathrm{MOIH}$ and $\mathrm{CHH}$ activities is indeed $\mathrm{CHH}$ as defined by sequence characteristics (28). The lobster $\mathrm{CHH}$ (23) and spider crab $\mathrm{CHH}$ (27), which respectively have $\mathrm{MIH}$ and $\mathrm{MOIH}$ activities, represent initial examples illustrating pleiotropy of these family members, which was frequently reiterated by later studies. The observations that some member peptides, in particular $\mathrm{CHH}$, are pleiotropic and often overlap with biological activities of other members probably reflect the evolutionary history of the $\mathrm{CHH}$ family (29-31). Based on the structure of the genes and the hormone precursors, and the characteristics of the mature peptides, the $\mathrm{CHH}$-family peptides were divided into two groups: Type I (CHH) and Type II (MIH/ GIH/MOIH) (30, 32-34).

Increasingly, the $\mathrm{CHH}$-family peptides have been identified more through nucleotide sequencing of transcripts (cDNA cloning or transcriptomics) than by the conventional approach of biochemical purification and peptide sequencing. In a recent report, in silico mining of transcriptome datasets from 112 crustacean species (representing three Classes: Malacostraca, Branchiopoda, Copepoda) resulted in a collection of 413 genes encoding $\mathrm{CHH}$-family peptides (35). The $\mathrm{CHH}$ family has been expanded to the status of a superfamily as more member peptides are identified in non-crustacean species. The first non-crustacean member of the $\mathrm{CHH}$-superfamily is the ion transport peptide (ITP), which was isolated from the corpora cardiaca of the desert locust Schistocerca gregaria and has structural characteristics that allow it to be integrated into the Type I group (36-38). The presence of the $\mathrm{CHH}$-superfamily peptides is firmly established through in silico mining of data derived from several representative ecdysozoan clades [e.g., $(31,39-42)]$. Recently, the $\mathrm{CHH}$ superfamily has been expanded by addition of latrodectin peptides and HAND (helical arthropod-neuropeptide-derived) toxins present in the venoms of spiders and centipedes $(43,44)$. The fact that the $\mathrm{CHH}$-superfamily peptides are expressed across the Ecdysozoa has singularly complicated our functional and 
phylogenetic understanding of the different members of the superfamily. Nevertheless, this diversity now gives timely opportunities to better understand the evolution of the $\mathrm{CHH}$ superfamily. Indeed, the grouping of the $\mathrm{CHH}$-superfamily peptides has been revised according to analyses accommodating the newly discovered peptides, thus creating two new types: Type III and Type IV $(31,45)$. Investigation of the structure-function relationships of the peptides can now benefit as more structural variants with novel functions are available for comparative study, as exemplified by the structural study of HAND toxins (43).

The existence of multiple copies of genes encoding the crustacean members of the $\mathrm{CHH}$ superfamily increases the structural diversity of the member peptides, although the physiological significance of such structural polymorphism has not been fully clarified $(29,30)$. Alternative splicing of RNA also contributes to the structural diversity of the Type-I peptides $(37,46-55)$. Thus, at the mature peptide level, two peptides are derived from a common transcript, a short-splice form (CHH or ITP) and a long-splice form (CHH-L or ITP-L), which share the same sequence for the first 40 residues from the N-terminal end but differ considerably after the $40^{\text {th }}$ residue (56, 57). The peptides of the long-splice form have been far less characterized functionally than their short-splice counterparts. Recent studies utilizing RNA interference (RNAi), however, have shed some light on their functions (58-60). Structural diversity is further augmented by a post-translational isomerization of specific residues ( $\mathrm{Phe}^{3}$ in $\mathrm{CHH}$ and $\operatorname{Trp}^{4}$ in $\left.\mathrm{GIH}\right)$, resulting in a change in the configuration of the residue from L-form to D-form (61), which modifies the functionality of the peptides (62-66).

While the XO-SG complex in the eyestalk is the first tissue from which the crustacean members of the $\mathrm{CHH}$ superfamily were isolated and most likely the main source of these peptides, it has been shown that they are also expressed in other nervous and non-nervous tissues [e.g., (47, 48, 50, 53, 55, 67-72)]. Similarly, ITP and ITP-L are widely expressed in the central and peripheral nervous system $(49,73,74)$. The broad tissue expression of the $\mathrm{CHH}$-superfamily clearly attests to their functional importance and might be closely related to the observed pleiotropy of these peptides. Physiologically adaptive roles of $\mathrm{CHH}$ have been put to test using animal models that undergo life-history stages that presumably require regulation by $\mathrm{CHH}(75,76)$. Recently, the metabolic effects of $\mathrm{CHH}$ on the muscle and hepatopancreas of the crayfish Procambarus clarkii were comprehensively characterized using a metabolomic analysis, revealing that the effects are more wide-ranging than previously realized and that the two tissues are differentially regulated by $\mathrm{CHH}(77,78)$. The metabolic effects of $\mathrm{CHH}$ have also been implicated in the pathogenesis of diseases in infected crustaceans (77-81). On the other hand, several studies suggested that $\mathrm{CHH}$ modulates the immune functions $(82-84)$, although the proposed immunomodulatory effects of $\mathrm{CHH}$ have not been thoroughly assessed in pathologically relevant conditions. It is entirely possible that an observed functional change in response to $\mathrm{CHH}$ treatment may be due directly to metabolic effects (especially energy metabolism) of $\mathrm{CHH}$, as already suggested by several authors $(70,75,85,86)$. The fact that a given peptide member could be expressed in multiple tissues complicates physiological investigations. A case in point is the ecdysisassociated hemolymph surge of $\mathrm{CHH}$ that is released from gut endocrine cells, not the eyestalk XO-SG complex (68). The mode of action, endocrine or autocrine/paracrine, would be another issue that should attract the interest of physiologists working on the function of these peptides.

Structure-function relationships have been comprehensibly studied for MIH of Marsupenaeus japonicus (Pej-MIH), ITP of S. gregaria (Scg-ITP), and CHH of Scylla olivacea (Sco-CHH) using mutated recombinant peptides (87-90). Moreover, the threedimensional structure of three crustacean member peptides (Pej$\mathrm{MIH}, \mathrm{Pej}-\mathrm{CHH}-\mathrm{Gly}$, and Sco-CHHL) and that of a HAND toxin (Ta1a) are available for comparison $(43,91-93)$. Several functionally important residues, as assessed by the studies of the structure-function relationships are located in the parts of the structure that are in close proximity, which are likely involved in receptor binding and activation (87-90, 93). An exciting and important discovery in the field of study of the $\mathrm{CHH}$ superfamily is the identification of three orphan $\mathrm{G}$ protein-coupled receptors (GPCRs) as receptors for the silkworm Bombyx mori ITP and ITP-L (94), which subsequently led to identification of several crustacean GPCRs as the candidate receptors for crustacean member peptides of the superfamily, $\mathrm{CHH}$ or $\mathrm{MIH}$ (95-97). Identification of the receptors would give great impetus to many aspects of functional studies, including confirmation of target tissues, functional specificity (and overlap), and the cellular mechanism of action coupled to receptor activation.

This review is intended to highlight and discuss the progress that has been made in the past decade or so in the field of study of the $\mathrm{CHH}$ superfamily within the general framework of the knowledge accumulated since almost a century ago. Readers are also referred to reviews on similar topics that have been recently published $(56,98)$.

\section{EVOLUTION AND STRUCTURAL DIVERSIFICATION OF THE SUPERFAMILY}

\section{Genomic Diversity}

Isoforms of $\mathrm{CHH}$ were firstly characterized with regard to their specific functions. For example, CHHs sensu stricto are pleiotropic hormones mainly involved in the regulation of metabolism or water and ion balance, or may even have a negative effect on reproduction and molting. However, $\mathrm{MIH} /$ GIH/MOIH seemingly have, in the current state of our knowledge, more limited functions. These functional differences are obviously associated with structural differences which have enabled them to be distinguished and classified as distinct types, such as Type I and Type II, respectively (33). Type I brings together peptides with a cryptic sequence or PRP (precursor related peptide) and a dibasic cleavage site upstream of the mature peptide sequence. Type II is characterized by the absence of this PRP and has a glycine residue in position 5 after the first cysteine (33-35). It is important to keep in mind that if the first sequences were obtained from an identified biological 
function, this is no longer the case for most member peptides identified subsequently, as most have been characterized mainly by high-throughput sequencing techniques.

$\mathrm{CHH}$-superfamily members are clearly no longer restricted to crustaceans, since ITP (ion transport peptide) was found in locusts $(37,38)$. ITP has since been found not only in other hexapods but also in chelicerates (39-42, 44, 99-101) and nematodes (102). ITPs were initially believed to be specific to non-crustaceans until they were identified in non-malacostraca crustaceans such as phyllopods $(31,103,104)$, copepods $(105-$ 107), and remipedes (108). In these species, the presence of ITP seems to be exclusive since no other $\mathrm{CHH}$ peptide has been characterized simultaneously. This isoform presents a precursor organization closer to that of $\mathrm{CHH}$ s than $\mathrm{MIH} / \mathrm{GIH} / \mathrm{MOIH}$, i.e., the presence of a PRP and a dibasic cleavage site, which has led to its inclusion in Type I (31). However, phylogenetic studies, carried out on the basis of sequences of the three isoforms, clearly place the ITPs, including those obtained from nonmalacostracan crustaceans and hexapods, at the base of Types I and II. This observation led to the proposal to create a third group, Type III, which brings together all these ITP orthologues $(31,45)$.

The analysis of recent transcriptomes has added another level of complexity by identifying a new form of peptide belonging to the superfamily $(45,109,110)$. These new sequences possess the six conserved cysteine residues, but do not have a PRP sequence, nor a dibasic cleavage site or the glycine residue, a signature of MIH (45). They are also significantly longer than other isoforms with more than 80 amino acids. Nevertheless, their BLAST hit clearly clusters them with ITP isoforms of insects and Cladocera crustaceans such as Daphnia rather than CHHs or MIH/GIHs. For this reason, they have been grouped together under the name ITP-like (45). Thus, inclusion of ITP-like sequences in a phylogenetic analysis conducted on more than 200 sequences of family members confirms their belonging to the same group and positions them as an independent group (45). The features of their sequences exclude them from the types currently recognized and once again question the dichotomous classification proposed by Lacombe et al. (33). It constitutes a new set of members in the same way as CHHs sensu stricto or MIHs and would thus form a fourth type (Type IV), if we refer to phylogeny.

The analysis of the different transcriptomes also addresses the number of isoforms, notably $\mathrm{CHHs}$, present within each species. Information collected from these analyses revealed the presence of many additional isoforms within each species, which are growing more numerous as the number of tissues analyzed has increased. While there are so far only one or two isoforms of MIH/GIH (111-116), CHH peptides exhibit much greater variety with commonly four or more different isoforms (45, 117). The presence of multiple chh genes has been demonstrated in decapods, (up to nine) whereas only one copy of the itp gene is present in insects $(29-31,57)$. Similarly, only two mih genes have been identified in several species $(111,118)$. Some are clearly derived from recent duplications and show little divergence (119), while others differ substantially from the most represented isoforms and clearly demonstrate that diversity has been underestimated (45). It is very likely that additional transcriptomic analyses will uncover new isoforms, even in species that have already been well studied (119). This diversity supports the importance of this molecular family at the physiological level and could also explain the apparent pleiotropy of the CHHs.

Beyond this genomic diversity, there are mechanisms in some crustaceans that can produce new isoforms by post-transcriptional or post-translational modification, as detailed below.

\section{Post-Transcriptional Modifications}

Alternative splicing of the $c h$ gene in pericardial organs of $C$. maenas (47) results in a $\mathrm{CHH}$ isoform that lacks the defining activity of $\mathrm{CHH}$. Alternative splicing has since been demonstrated for several $\mathrm{CHH}$ genes in malacostracan crustaceans $(47,48,53$, $60,72,120)$ but also for insect ITPs $(51,52,57,59)$. These splicing patterns originate in the structure of the chh or itp genes, which have a minimum number of four exons. The splicing alternates two exons (exon 3 or 4) as the terminal part of the transcript, resulting in two transcript forms - the short-splice forms (exons 1, 2,4 ) and the long-splice forms (exons $1,2,3,4$ ), in which the stop codon is located at the end of the third exon, leaving the fourth exon untranslated (Figure 1). This process generates two peptides from a single gene that differ in sequence after the $40^{\text {th }}$ amino acid residue of the mature peptide. Exons 3 and 4 both encode peptide sequences of similar lengths, with two cysteine residues in the same positions, thus suggesting that alternative exon 4 appeared by tandem duplication of exon 3, or vice versa (31). The transcripts of the short-splice forms of $\mathrm{CHH}$ peptides were mainly found in neurons of the central nervous system (more precisely in the X-organ located in the eyestalk), whereas the longsplice forms were found in neurons of the peripheral nervous system and non-nervous tissues, thoracic ganglia, Y-organ, mandibular organ or hemocyte according the species (47, 48, $55,60,70,121)$. Peptides encoded by the long-splice forms of $\mathrm{CHH}$ and ITP transcripts are slightly longer than peptides encoded by the short-splice transcripts and are never Cterminally amidated [see (56)]. They are named CHH-L and ITP-L, respectively. In addition to these genes with four exons, there are also genes with only three or even two exons, such as the majority of $\mathrm{CHH}$ isoforms of penaeid shrimps. $\mathrm{MIH}$ and $\mathrm{MOIH}$ are encoded by genes with three exons (29, 31, 122, 123). Alternative splicing mechanisms, as described here, have never been reported for these two- or three-exon genes of penaeid shrimps. It is also interesting to note that this splicing process can generate "truncated" forms of $\mathrm{CHH}$ as demonstrated in the hemocyte of the crayfish P. clarkii (72), resulting in a precursor, where the mature peptide sequence is truncated with only the first 40 residues.

\section{Ubiquity of the CHH-Superfamily Peptides}

The following examples underline the widespread ubiquity of the $\mathrm{CHH}$ superfamily members, which demonstrates the surprising 


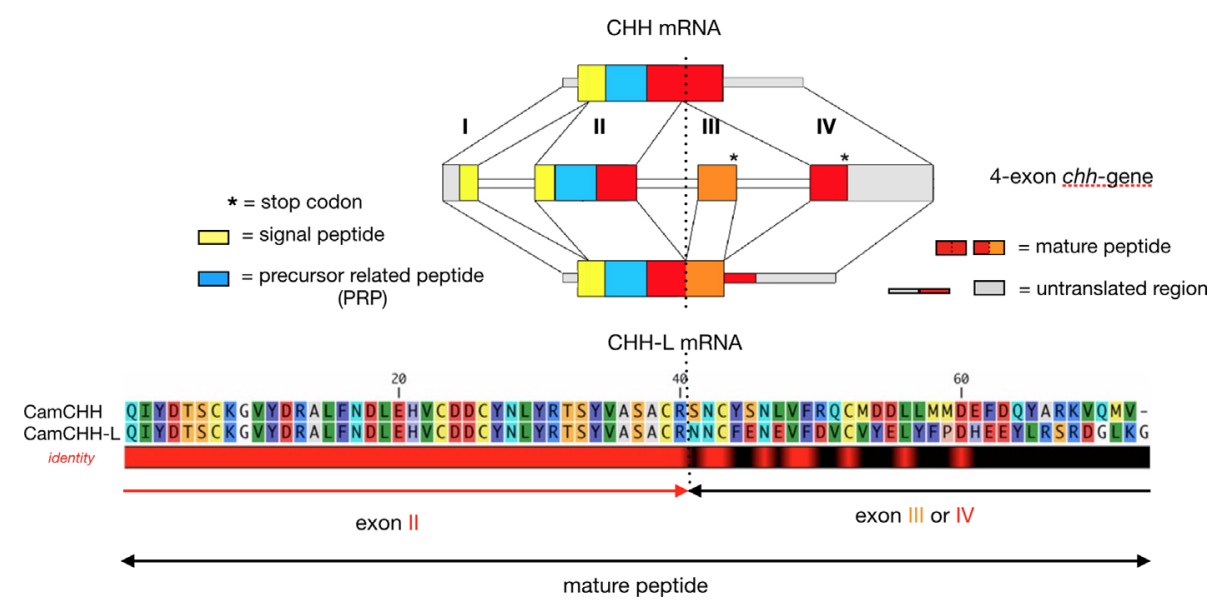

FIGURE 1 | RNA alternative splicing of the chh gene in the shore crab Carcinus maenas. C. maenas chh gene is a 4-exon gene. The long-splice form (CHH-L mRNA) consists of exon I, II, III, and IV, and the short-splice form (CHH mRNA) consists of exon I, II, and IV. The first 2 exons (exon I and II), which encode the signal peptide, the precursor-related peptide (PRP), and the first 40 residues of the mature peptide, are common to the two splice forms. The remaining sequence of the $\mathrm{CHH}-\mathrm{L}$ and $\mathrm{CHH}$ mature peptide is encoded by exon III and IV, respectively. Note that both exon III and IV have a stop codon. The dashed line marks the splice site.

diversity of these peptide isoforms and their functions. Indeed, if the first isoforms were characterized at the level of neural ganglia, first in the XO-SG complex in the eyestalks and then followed by the thoracic ganglia, the detection of these peptides in other tissues is becoming increasingly common. The first evidence was provided by immunocytochemical analysis in C. maenas, in cells located at the fore and hindgut level, suggesting a mechanoreceptive function. These are "paraneurones" which secrete $\mathrm{CHH}$ into the hemolymph during ecdysis $(68,124)$. Since then, it has been shown that $\mathrm{CHH}$-related peptides are expressed in a wide variety of tissues including the pericardial organ $(120,125)$, retina $(126)$, gill $(60,127)$, spermatophore $(71$, $128)$, Y-organ $(121,129)$, hemocyte $(70,72)$, ovary $(129,130)$, stomach (130), and intestine (54).

Until recently, it was thought that MIH/GIH/MOIH peptides were only expressed in neuronal tissues of the XO-SG system. However, MIH expression has been identified in the heart of the shrimp Litopenaeus vannamei (131), and in the gill, ovary, and abdominal ganglion of Macrobrachium nipponense, though at relatively lower level than in the eyestalks (132).

\section{Post-Translational Modifications}

In parallel with gene multiplication or post-transcriptional processes such as alternative splicing, peptide modification in some taxa further increases the diversity of isoforms and functions of Type I or II members. This mechanism, hitherto restricted to Astacidea in crustaceans but present as well in other arthropods such as arachnids and mollusks and a few vertebrates, involves production of peptides in which the chiral form of a single amino acid has been modified, i.e. from the L-enantiomer to the D-enantiomer (61). Thus, lobsters and crayfish have $\mathrm{CHH}$ isomers that are differentiated by the configuration of the $\mathrm{Phe}^{3}$, as either an L-form or a D-form. Both isomers exhibit the defining hyperglycemic activities and regulate energy metabolism, but the change in configuration results in modification of the biological activity of the peptide $(64,66$, 133). In particular, the hyperglycemic response kinetics are delayed with $\mathrm{D}-\mathrm{Phe}^{3}-\mathrm{CHH}$ ( 3 to $4 \mathrm{~h}$ instead of $2 \mathrm{~h}$ for the Lisoform), and the amplitude of the hyperglycemic response is increased $\left(10 \mathrm{x}\right.$ higher for $\left.\mathrm{D}-\mathrm{Phe}^{3}-\mathrm{CHH}\right)$. Additional functional changes for $\mathrm{D}-\mathrm{Phe}^{3}-\mathrm{CHH}$ were reported as having more potent inhibitory activity on the molting gland during ecdysteroidogenesis (65) or having a higher osmoregulatory activity $(62,63)$.

A similar modification from L-GIH to D-GIH has also been demonstrated in three Nephropidae species (American, European, and Norway lobsters). In this case, the modification is located at the level of the fourth $\mathrm{N}$-terminal amino acid, a tryptophan $(134,135)$. However, the function of $\mathrm{D}-\operatorname{Trp}^{4}-\mathrm{GIH}$ is still unknown, as it does not display significantly inhibitory effect in a heterologous in vivo assay as its counterpart does.

The study of the maturation dynamics of the $\mathrm{CHH}$ isomers highlighted the different stages of the post-translational processing of the precursor (Figure 2). It appears that isomerization takes place after cleavage of the pro-peptide and before N-terminal cyclization $(136,137)$. The production of antibodies specifically directed against the two $\mathrm{CHH}$ isomers made it possible to monitor in situ their location during the maturation process in the XO-SG complex of eyestalks of the crayfish O. limosus and the lobster $H$. americanus $(135,136)$. Two cell types producing either $\mathrm{L}-\mathrm{CHH}$ exclusively (L-CHH cell) or a mixture of both L- and D-isomers (D-CHH cell) were identified (Figure 2). Most of the transformation of the Lisomers seems to occur in the cytoplasm, before the granules penetrate the axons (138). A similar approach was conducted with GIH isomers. Differential localization of the two isomers in different cells was characterized, as for CHHs. In the same way, simultaneous monitoring of the four isomers showed co- 


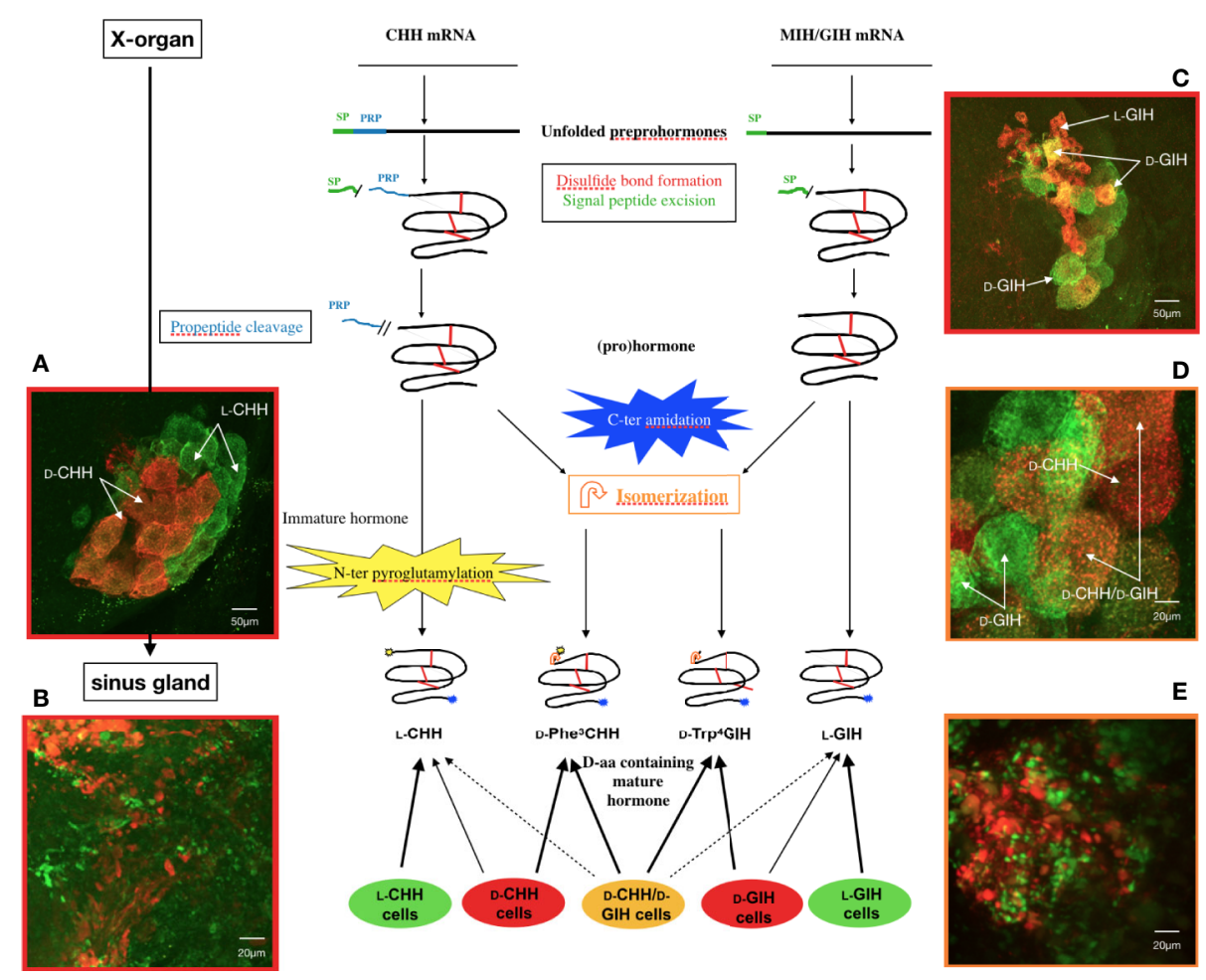

FIGURE 2 | State of the current understanding of L- to D- isomerization in Homarus americanus. General diagram of precursor processing of CHH and GIH isomers in relation to the different cell types in the X-organ-sinus gland complex and confocal micrographs of double labeled whole mounts of lobster Homarus americanus. Amidation can occur pre-, co- or post-cleavage of PRP. Cyclization of the $\mathrm{N}$-terminus of $\mathrm{CHH}$ is optional (i.e., $\mathrm{N}$-terminus unblocked $\mathrm{CHH}$ can be released) and, similarly to isomerization, it occurs after PRP cleavage. GIH is not N-terminally cyclized (by pGlu). SP, signal peptide; PRP, precursor-related peptide. (A) Distribution of $\mathrm{CHH}$ cells in the $\mathrm{X}$-organ showing green somata $(\mathrm{L}-\mathrm{CHH}$ cells) and orange somata ( $\mathrm{D}-\mathrm{CHH}$ cells). (B) Axon terminals in the sinus gland showing secretory granules in $\mathrm{L}-\mathrm{CHH}$ cells (green) and D-CHH cells (red). (C) General view of the X-organ visualizing small L-GlH cells (red) and larger D-GIH cells (green or yellow). L-CHH and LGIH cells secrete exclusively $\mathrm{CHH}$ and $\mathrm{GlH}$, respectively, whereas $\mathrm{D}-\mathrm{CHH}$ and $\mathrm{D}-\mathrm{GlH}$ cells release mainly the $\mathrm{D}$-isomer of the respective hormone, in addition to a variable amount of L-isomer. (D) Immunolocalization of D-Trp ${ }^{4} \mathrm{GIH}$ and D-Phe ${ }^{3} \mathrm{CHH}$ in the X-organ where three cell types were observed: D-CHH cells (red), D-GIH cells (green) and D-cells producing both D-isomers (orange). D-cells secrete mainly the $\mathrm{D}$-form of both $\mathrm{CHH}$ and GlH. Besides isomerization, the same posttranslational processes occur in every type of $\mathrm{CHH}$ or GIH cell. (E) Sinus gland axonal arborizations containing D-Trp ${ }^{4} \mathrm{GlH}$ (green) and D-Phe ${ }^{3} \mathrm{CHH}($ red) (135).

localizations within the same cells. Only L-GIH and L-CHH could not be found together (135) (Figure 2).

These studies have highlighted a particularly original mechanism of post-translational modification and curiously, so far, this has been demonstrated only in Astacidea crustaceans. Because this L-to D-post-translational modification is subtle and not detectable by most sequence determination approaches, it cannot be excluded that it exists in other taxa, although it has been searched for in other crustaceans, without success. Nevertheless, this process is not specific to crustaceans. As mentioned above, it has not only been found in arachnids, but also in molluscs, tetrapods, and mammals (61).

Another post-translational modification, a C-terminal amidation event, seems particularly important to limit degradation of the peptides by carboxypeptidases (139). The C-terminal amidation concerns only $\mathrm{CHH}$ and ITP, while the long-splice form (CHH-L or ITP-L) do not present this modification. In addition to the protective role in resisting degradation, the amidation is also important for the activity of the peptides, since the amidated peptides, compared to the unamidated ones, have more potent activities (139-141). This posttranslational modification has also been infrequently observed in type-II peptides such as GIH or MIH, although the functional significance of the modification is not clear $(132,142,143)$. Like the C-terminal extremity, the $\mathrm{N}$-terminus has, again only for $\mathrm{CHH}$ and ITP, a post-translational conversion via cyclization of the terminal Glu or Gln residue into pyroGlu $(56,57)$. This modification would protect the $\mathrm{N}$-terminus from degradation by aminopeptidases, but does not significantly change the biological activities of the peptide, as the N-terminally unblocked and blocked $\mathrm{CHH}$ s of $C$. maenas were shown to be almost distinguishable in the activities of elevating hemolymph glucose levels and of repressing ecdysteroid synthesis (144).

\section{Weaponization of the $\mathrm{CHH}-$ Superfamily members?}

Among the peptides characterized with D-amino acyl residues, it is interesting to note that there are many examples of these molecules 
that have been extracted from venoms or the nervous system (145, 146). This link between members of the $\mathrm{CHH}$ superfamily and venom peptides was further strengthened by the discovery that certain peptides of low molecular weight identified in black widow spider venom (genus Latrodectus), e.g., the latrodectins, show sequence similarities with $\mathrm{CHH}$, particularly in terms of size, around 70 residues, the signature of the six conserved cysteines including similar disulfide bond pairing, and a similar alpha-helical structure (99). Further analyses suggested that $\mathrm{CHH}$-superfamily peptides might have been recruited for venom expression at least three times: once in Hymenoptera, once in scorpions, and at least once in spiders, each lineage independently evolving venom production (44). However, the functional role of the latrodectins remains unclear as they are not insecticidal or toxic to mice (99), nor do they produce hyperglycemic effects when injected into crabs, crayfish, or shrimps (147).

An exception was however first identified in the venom of common agelenid spider Tegeneria agrestis, the U1-agatoxinTala $(148,149)$, and then discovered in the venoms of members of the centipede genus Scolopendra, representing convergent recruitment of $\mathrm{CHH}$-superfamily peptides into the toxin arsenals of these myriapods (43). Despite a weak sequence identity, the structure of MIH of the shrimp M. japonicus and $\mathrm{CHH}-\mathrm{L}$ of the crab $\mathrm{S}$. olivacea are surprisingly topologically similar to that of Tala. However, the N-terminal $\alpha$-helix $(\alpha 5)$, present in both $\mathrm{MIH}$ and $\mathrm{CHH}-\mathrm{L}$, is absent from Tala [Figure 3; also see (43)] and the loss of this helix could be a key step in weaponization of $\mathrm{CHH}$ family peptides (43).

Recently, a proteomics approach of the venom components of the parasitoid wasp Tetrastichus brontispae resulted in the identification of, among a large number of diverse proteins or peptides, three ITP-L (ITPLn1-3) as abundant toxins (150). These ITP-Ls are distinct from ITPs by the implementation of a possible alternative splice allowing diversification of the gene products and a potential neo-functionalization that would lead to an evolution towards peptides of the $\mathrm{CHHs}$ family with venomous properties.

The mechanisms for recruiting members of the $\mathrm{CHH}$ superfamily as toxins are clearly varied and appear to have evolved independently in the different taxa. Nevertheless, the use of ITP/CHHs as evolutionary fodder for these transformations is a consensus among a growing number of species and is certainly not fortuitous. The structural properties ( 3 disulfide bridges which guarantee great stability), the multiplicity of genes and the posttranscriptional or even post-translational mechanisms are all processes that can lead to neo-functionalization, of which the acquisition of toxicity is one. In this context, one of the consequences of the acquisition of a D-amino acid peptide is a higher resistance to proteases and therefore a longer half-life for these peptides (146). In the future, it would not be surprising to find organisms with venomous ITP/CHHs carrying this type of modification.
A

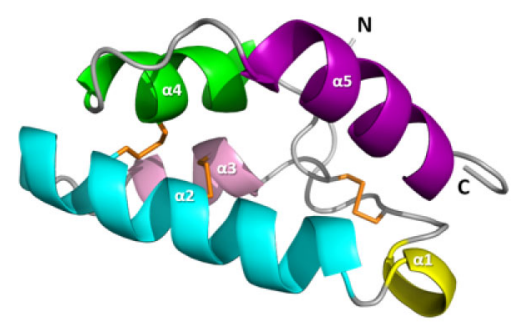

Pej-MIH

C

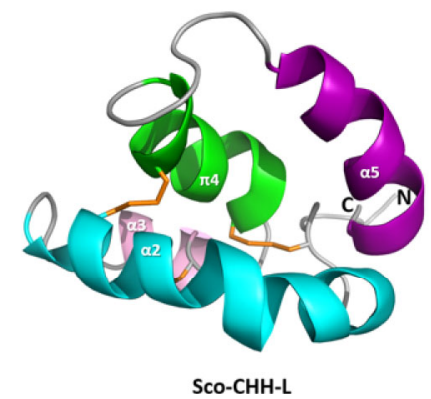

B

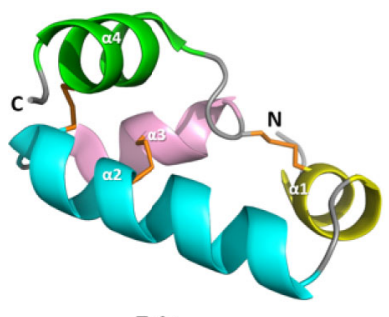

Ta1a

D

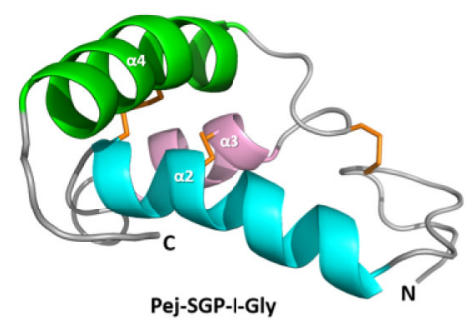

FIGURE 3 | Structure of the spider toxin Ta1a and representative crustacean member peptides. Ribbon structure of (A) Pej-MIH, (B) Ta1a, (C) Sco-CHH-L, and (D) Pej-SGP-I-Gly. The helices, and $\mathrm{N}$ - and C-terminus ( $\mathrm{N}$ and $\mathrm{C}$ ) are labeled. Note the absence of the terminal helix ( $\alpha 5)$, which is present in both $\mathrm{MlH}$ and $\mathrm{CHH}$ - $\mathrm{L}$, from Ta1a and Pej-SGP-I-Gly. A $\pi$ helix $(\pi 4)$, topologically equivalent to the $\alpha 4$ in other structures, is present in Sco-CHH-L. Protein Data Bank IDs for the structures are respectively 1JOT, 2KSL, 5XS1, and 5B5I. 


\section{BIOLOGICAL FUNCTIONS}

\section{Type-I and III Peptides}

$\mathrm{CHH}$ and ITP were functionally defined by the hyperglycemic activity and stimulation of trans-epithelial $\mathrm{Cl}^{-}$transport in the ileum, respectively, which formed the basis (by bioassay) for purification, chemical characterization, and eventual identification of the hormones $(19,22,37,38,151,152)$. Studies over the years have however revealed that the two peptides are more functionally conserved than the initial defining functions would have suggested.

\section{Metabolism, lonic and Water Homeostasis, and Development (CHH, ITP, CHH-L, and ITP-L)}

A "diabetogenic factor", as the presumptive factor elevated hemolymph glucose levels, in the crustacean eyestalks was suggested more than 7 decades ago (153). It is generally accepted, based on early studies, that $\mathrm{CHH}$ mobilizes glycogen reserves in the $\mathrm{CHH}$ target tissues (e.g., the hepatopancreas and muscle), leading to hyperglycemia via regulation of the amount and activity of the enzymes (glycogen synthase and glycogen phosphorylase) involved in glycogen metabolism (154-159). The increased availability of glucose for cells, resulting from the glycogen-mobilizing effect of $\mathrm{CHH}$, may subsequently stimulate the glycolytic flux $(160,161)$. The stimulatory effects of $\mathrm{CHH}$ on the release of amylase from the hepatopancreas (162) and hemolymph levels of triacylglycerols and phospholipids (163) have been reported but not further characterized. Recently, the metabolic roles of $\mathrm{CHH}$ in the crayfish P. clarkii were more comprehensively characterized using an RNAi approach (double-stranded RNA) followed by profiling the hepatopancreas and muscle metabolomes $(77,78)$. The combined data indicated that $\mathrm{CHH}$ has more diverse effects than previously realized, and the two target tissues are differentially regulated. The main effects of $\mathrm{CHH}$ are stimulation of glycolysis and lipolysis in the hepatopancreas, and higher rate of utilization of carbohydrates (glucose and other sugars, including fructose, galactose, sucrose, and lactose) via glycolysis and TCA cycle (resulting in higher levels of ATP), stimulation of the pentose phosphate pathway (PPP) flux (leading to increased levels of nucleotide biosynthesis), and elevation of amino acid biosynthesis in the muscle $(77,78)$. Stimulation of the "Nicotinate and nicotinamide metabolism", which concerns the metabolism of two nicotinamide coenzymes $\left(\mathrm{NAD}^{+}\right.$and $\mathrm{NADP}^{+}$), is central to the metabolic effects of $\mathrm{CHH}$ in the muscle. Thus, the higher levels of $\mathrm{NAD}^{+}$(and higher $\mathrm{NAD}^{+} / \mathrm{NADH}$ ratio) and $\mathrm{NADP}^{+}$, respectively, drive these fluxes through glycolysis, the TCA cycle, and the PPP $(77,78)$. The tissue-specificity of $\mathrm{CHH}$ regulation is consistent with the results showing the transcript expression of carbohydrate metabolismrelated enzyme genes were differentially regulated by $\mathrm{CHH}$ in the same two tissues of M. japonicus (159). A proposed scheme for the metabolic roles of $\mathrm{CHH}$ in the two target tissues is shown in Figure 4, based on combined data from several related studies.

A substantial amount of evidence has been accumulated indicating that $\mathrm{CHH}$ is involved in regulating osmotic homeostasis. It was first reported in the American lobster H. americanus that sinus gland extracts increased the osmoregulatory capacity of eyestalkablated animals kept at low salinity (164). A CHH variant, specifically D-Phe ${ }^{3}-\mathrm{CHH}$, when injected was able to significantly compensate the eyestalk ablation-induced decrease in hemolymph osmolality, $\mathrm{Na}^{+}$ concentration, or both, in H. americanus (164) and the freshwater crayfish Astacus leptodactylus (63); $\mathrm{CHH}$ stimulated in vitro trans-

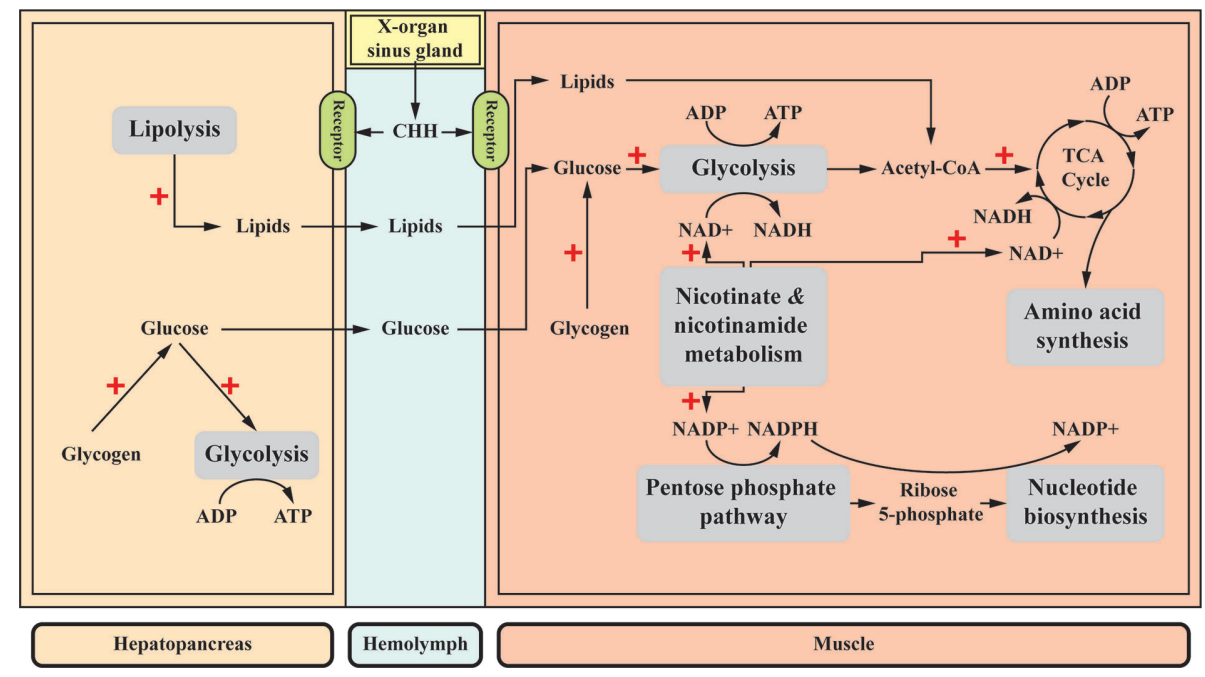

FIGURE 4 | A proposed scheme for the metabolic roles of $\mathrm{CHH}$ in the muscle and hepatopancreas. $\mathrm{CHH}$ differentially regulates its target tissues. $\mathrm{CHH}$ decreases glycogen accumulation in both target tissues, resulting in higher levels of glucose (154-158) that drives glycolytic flux (160, 161). Moreover, in the hepatopancreas, $\mathrm{CHH}$ enhances lipolysis $(77,163)$. Glucose and lipids are released into the hemolymph and taken up by the muscle where they are further metabolized via glycolysis and TCA cycle, respectively, for ATP production. In the muscle, central to the effects of $\mathrm{CHH}$ is a stimulated "Nicotinate and nicotinamide metabolism", which provides two nicotinamide coenzymes ( $\mathrm{NAD}^{+}$and $\mathrm{NADP}^{+}$) that drive glycolysis and TCA cycle, and the pentose phosphate pathway, respectively, resulting in increased ATP supply and biosynthesis of amino acids and nucleotides $(77,78) .+$, stimulatory effects. 
epithelial electrical potential difference and $\mathrm{Na}^{+}$influx in the posterior gills in the crab Pachygrapsus marmoratus (165) and was effective in restoring stress-induced decrease in hemolymph $\mathrm{Na}^{+}$ and $\mathrm{K}^{+}$levels to the pre-stress levels in the freshwater crayfish Cherax quadricarinatus (85). High-affinity $\mathrm{CHH}$ binding sites were identified in, among other tested tissues, the gill of $C$. maenas and in vitro treatment of the gill with $\mathrm{CHH}$ significantly increased both cGMP and glucose levels in the tissue (86). In a study exemplifying the physiological roles of $\mathrm{CHH}$ at specific life-history stages, a gut-derived $\mathrm{CHH}$, which was massively released into hemolymph during late pre-molt and ecdysis, was suggested to be involved in stimulating water and ion uptake in the crab $C$. maenas, causing body swelling for successful ecdysis and subsequent increase in animal size during post-molt (68). While these studies strongly implicate $\mathrm{CHH}$ as an important factor for iono/osmoreguation, the molecular target(s) on which $\mathrm{CHH}$ acts to achieve its regulatory activity were not directly addressed by these studies. It is however relevant to note that $\mathrm{CHHs}$ of the Christmas Island blue crab Discoplax celeste, which stimulated $\mathrm{Na}^{+}$transport across the gill epithelia, had no effect on gill $\mathrm{Na}^{+} /$ $\mathrm{K}^{+}$-ATPase or V-ATPase activity (75).

Characterization of the functional roles of $\mathrm{CHH}$ has led to the concept that $\mathrm{CHH}$ acts physiologically as a stress hormone (166). In various crustacean species, it has been shown that $\mathrm{CHH}$ mediates the stress-induced hyperglycemia in animals exposed to different stressors (extreme temperature, hypoxia, organic and inorganic pollutants, etc.), presumably metabolically acclimating animals to the stressful environment (50, 167-171). Interesting and insightful observations have been reported in studies working on crustaceans with distinct seasonal patterns of physiological demands $(75,76)$. The Christmas Island red crab (Gecarcoidea natalis) and blue crab (D. celeste) are two terrestrial brachyurans that undergo annual breeding migration towards the sea at the beginning of the wet season but remain inactive and fossorial during the dry season, and as such, were considered ideal species for investigating the roles played by $\mathrm{CHH}$ in metabolic and ionic homeostasis in an eco-physiological context as the endocrine status with respect to energy metabolism and osmoregulation should change seasonally (75, 76). One of the main findings derived from these studies is that in both species, while a 10-min extreme (forced) exercise stimulated a rapid and transient $\mathrm{CHH}$ release into the hemolymph followed by increases in hemolymph glucose levels, the hemolymph $\mathrm{CHH}$ levels in the migrating animals were actually significantly lower than those found in the animals during the dry season. This is in contrast to what would have been presumed based on the expected metabolic burden of the migration activity on the animals. It was further demonstrated that a negative feedback loop involving inhibition of $\mathrm{CHH}$ release by glucose existed only during the wet season but was uncoupled during the dry season. It was considered that the lower $\mathrm{CHH}$ levels in the wet season might be due to the inhibitory effect of high glucose levels, characteristic of migrating animals in the wet season when they continue to feed to conserve the glycogen stores that are to be utilized later for more strenuous activities, which deplete glycogen reserves upon the return migration. The significantly higher dry-season $\mathrm{CHH}$ levels, likely reflecting the lack of a functioning negative feedback loop at the time, might be metabolically advantageous when animals were fossorial with limited foraging activity (76). Alternatively, it was reasoned that the significantly higher $\mathrm{CHH}$ levels during the dry season, when conservation of water and ions would be crucial, might be closely related to the ionoregulatory activity of $\mathrm{CHH}$ (76). Indeed, experiments measuring branchial $\mathrm{Na}^{+}$flux indicated that $\mathrm{CHHs}$ affect sodium uptake in the gill in a season-dependent manner attesting to the importance of $\mathrm{CHH}$ for ionic and water homeostasis $(75,76)$. Data generated from these studies highlight the intricate and intriguing aspects of $\mathrm{CHH}$ regulation that must be shaped in ways to meet the physiological demands characteristic of particular stages of the life history of the animals. These studies underline the importance of such functional approaches both in the field and in the laboratory for improving our understanding of the adaptive significance of $\mathrm{CHH}$.

While $\mathrm{CHH}$ has been functionally characterized rather extensively, the functional role of $\mathrm{CHH}-\mathrm{L}$ has been far less studied. It is however known that $\mathrm{CHH}$-L, unlike $\mathrm{CHH}$, does not have either hyperglycemic or ecdysteroidogenesis-inhibiting activity $(47,172,173)$, and co-injection of $\mathrm{CHH}$ and $\mathrm{CHH}-\mathrm{L}$ did not change the pattern of hyperglycemic responses in C. maenas injected with $\mathrm{CHH}$ alone. This rules out the possibility that $\mathrm{CHH}-\mathrm{L}$ functions as a negative regulator of $\mathrm{CHH}$ (47). A recent study suggested that $\mathrm{Pt}-\mathrm{CHH} 2$, a CHH-L peptide of the crab Portunus trituberculatus, could be involved in regulating gill $\mathrm{Na}^{+} / \mathrm{K}^{+}$-ATPase and carbonic anhydrase activity, since $\mathrm{CHH}$ dsRNA treatment decreased $\mathrm{Pt}-\mathrm{CHH} 2$ transcript levels and significantly reduced the enzyme activity in the gills (60). Given that $\mathrm{CHH}$ is involved in osmotic regulation and that $\mathrm{CHH}$, at least in the Christmas Island blue crab D. celeste, has no effect on gill $\mathrm{Na}^{+} / \mathrm{K}^{+-}$ATPase or $\mathrm{V}$-ATPase activity (75), it is tempting to suggest that $\mathrm{CHH}$ and $\mathrm{CHH}-\mathrm{L}$ peptides are both physiologically relevant factors for regulating water and ionic balance. However, these peptides likely do so by acting on distinct molecular targets, perhaps in a concerted manner.

Ion transport peptide was first identified based on its antidiuretic activity in the ileum in the desert locust $S$. gregaria (36-38). ITP, released from the corpora cardiaca, stimulates the ileum to transport $\mathrm{Cl}^{-}$ion from lumen to hemolymph, driving water reabsorption. It is tempting to propose that ITP or ITP-L are involved in regulating processes critical for successful molting, as has been shown for $\mathrm{CHH}$ in crustaceans (68), but the evidence so far has not been conclusive [see (57)]. Studies using an RNAi method targeting expression of itp/itp-I transcripts in the red flour beetle Tribolium castaneum indicated that these peptides are important for adult eclosion, but less important for larval-larval or larval-pupal molting, based on observations of developmental defects and mortality (58). RNAi targeting expression of itp/itp-l in the brown planthopper Nilaparvata Lugens resulted in increased cuticle melanism and failed wing expansion (59). If and how the 
observed phenotypes during development are related to the water reabsorbing activity of ITP remain to be confirmed. In addition, because the phenotypes were mostly observed using dsRNA that simultaneously silenced itp and itp-l, the effects cannot be clearly assigned to individual peptides. Finally, functions of ITP are likely not limited to fluid reabsorption. In a recent study in Drosophila melanogaster, the roles of ITP have been extensively characterized as, not only enhancing water retention (estimated by the defecation rate), but also promoting thirst (estimated by the propensity to drink water and volume of water intake) and inhibiting intake of "dry food", which are thought to work collectively to protect the animals from dehydration (174).

\section{Pathogenesis and Immune Regulation (CHH)}

There have also been interesting developments with regard to the pathophysiological roles of $\mathrm{CHH}$. It has been shown in various crustacean species that a sub-lethal dose of lipopolysaccharide (LPS), a major component of the capsule of Gram-negative bacteria, elicited a significant hyperglycemic response (175), with a significant increase of hemolymph $\mathrm{CHH}$ levels as early as 30 min after treatment (80).

In another example in which $\mathrm{CHH}$ is implicated in a pathological condition, hemolymph glucose levels in the patently infected Norway lobster Nephrops norvegicus, parasitized by dinoflagellate Hematodinium sp., were dramatically decreased, indicating that the parasite, acting as a "carbohydrate sink", was absorbing glucose from the hemolymph of the host, leading to a near depletion of the glycogen reserve in the hepatopancreas of the lobsters with late stages of patent infection (81). The observations that hemolymph $\mathrm{CHH}$ levels progressively increased as the severity of infection increased, while glycogen reserves were significantly decreasing, vividly highlight the glycogen-mobilizing effect of $\mathrm{CHH}$. The opposite direction of changes in hemolymph glucose and $\mathrm{CHH}$ levels indicated that the negative feedback exerted by hemolymph glucose on $\mathrm{CHH}$ release is relieved in the patently infected hosts (81).

Similarly, in a study of white spot syndrome virus (WSSV) infection in $P$. clarkii, hemolymph $\mathrm{CHH}$ levels were significantly increased by WSSV. The virus-induced $\mathrm{CHH}$ release was rapid, commencing as early as $3 \mathrm{~h}$ post-infection, and long-lasting with the hemolymph $\mathrm{CHH}$ levels being significantly elevated for at least two days after the infection, leading to dramatic decreases in the $\mathrm{CHH}$ content in the eyestalk ganglia (79). However, hemolymph glucose levels in the infected hosts were not significantly higher than those in the uninfected animals, arguing for an enhanced glucose uptake by the host cells (79). Virus-induced alterations of metabolism, favoring viral replication and disease progression at the expenses of the host, have been reported in mammalian hosts [see (176)] and more recently also in crustaceans ( $M$. japonicus and Penaeus vannamei) (177, 178). Thus, infection of WSSV alters the metabolism in the host cells, collectively known as the "invertebrate Warburg effect", including a higher rate of glycolysis, the pentose phosphate pathway, ribonucleotide biosynthesis, glutaminolysis, and amino acid biosynthesis (177,
178), which are largely in accordance with the metabolic effects of $\mathrm{CHH}$, as revealed by two metabolomics studies $(77,78)$. In fact, analysis of the muscle metabolome using an enrichment analysis showed that the "Warburg Effect", among others, was significantly impacted when $\mathrm{CHH}$ expression was silenced (77). The combined data indicated that the virus-induced $\mathrm{CHH}$ release is at least partly responsible for inducing the Warburg effect (77-79). These studies illustrate how pathogens exploit the endocrine system of crustacean hosts, specifically increasing the $\mathrm{CHH}$ output and hence tilting the balance of host metabolism for the benefits of the pathogens. Silencing of chh gene expression was able to significantly decrease the viral load in the tissues and prolong the survival of the WSSV-infected P. clarkii (179).

Several reports studying the immunoregulatory effects of $\mathrm{CHH}$ in the Pacific white shrimp L. vannamei showed that recombinant $\mathrm{CHH}$ increased pathogen clearance and survival rates in pathogen-infected shrimps (82), and elevated total hemocyte count and the phagocytic activity of hemocyte (180). $\mathrm{CHH}$ treatment also affected the expression of several immune effector protein genes, including superoxide dismutase, LvRelish, and anti-microbial peptides, suggesting protective roles of $\mathrm{CHH}$ through modulating the immune activity of the shrimps (84, 180). It would be informative to investigate $\mathrm{CHH}$-modulated immune responses under pathogenic conditions, which are invariantly characterized by significantly higher $\mathrm{CHH}$ levels as has been previously reported $(79-81,175)$.

$\mathrm{CHH}$ transcripts encoding $\mathrm{CHH}$ and related peptides, including $\mathrm{CHH}$ and $\mathrm{CHH}-\mathrm{L}$ peptides and a novel truncated $\mathrm{CHH}$, have been reported in hemocytes of $P$. clarkii $(70,72)$. Production of $\mathrm{CHH}$ peptides was also demonstrated, with a cell type-specific expression pattern, and $\mathrm{CHH}$ was able to stimulate guanylyl cyclase activity in the hemocyte membrane preparations (70). Wu et al. (70) suggested that the hemocytederived $\mathrm{CHH}$ may act on hemocytes in an autocrine/paracrine manner, regulating carbohydrate metabolism in crustacean hemocytes as they have been shown to be an important site for carbohydrate storage and metabolism (181-183), or have direct roles in regulating immune responses of the hemocyte.

\section{Activities Overlapping With Those of Type-II Peptides (CHH)}

$\mathrm{CHH}$ has been implicated in regulating other biological functions, including activities that functionally define the Type-II peptides. Thus in various species, $\mathrm{CHH}$ has been found to inhibit ecdysteroid synthesis $(23,65,172,184,185)$, although its activity in this regard is less potent than $\mathrm{MIH}$ (65, $184,185)$, as well as methyl farnesoate synthesis (186). The physiological significance of $\mathrm{CHH}$-regulated ecdysteroidogenesis or methyl farnesoate synthesis has not yet been fully characterized. The functional overlap of $\mathrm{CHH}$ with the Type-II peptides may be the result of an evolutionary scenario in which the current $\mathrm{CHH}$ (Type-I lineage) retain a certain degree of the functional pleiotropy of an ancestral peptide, while the Type-II lineage evolved towards peptides with more specialized functions (31). 


\section{Type-II Peptides}

\section{Inhibition of Steroidogenesis in the Y-Organ by MIH}

Eyestalk ablation has been known for a long time to shorten molt interval and induce molting in many crustacean species. Based on these observations, Zeleny (7) proposed the existence of a "molt-inhibiting" factor in the eyestalk. Follow-up studies in various species have repeatedly shown that eyestalk ablation leads to an increase in ecdysteroid production by the Y-organ and in hemolymph ecdysteroid levels (187-189). This factor has since been purified, sequenced, and named molt-inhibiting hormone $(\mathrm{MIH})(20,24,184)$. Injection of recombinant MIH has been shown to prolong the inter-molt duration (190). Adding eyestalk extract or synthetic MIH to the incubation medium significantly diminished the secretion of ecdysteroids by the Y-organ in vitro $(191,192)$. Correspondingly, using ${ }^{125} \mathrm{I}$ $\mathrm{MIH}$ as the ligand, the existence of MIH-specific binding sites was detected in Y-organ membrane preparations from C. maenas (193), Callinectes sapidus (194), and M. japonicus (195). Altogether, these data strongly suggest that MIH acts directly on Y-organs to suppress ecdysteroidogenesis.

According to the above findings, a model has been proposed that the Y-organ ecdysteroidogenesis is suppressed by $\mathrm{MIH}$ during much of the molt cycle, only to be relieved from the suppression during the pre-molt stage, when MIH levels are low [see (196)]. Normally, hemolymph MIH levels are rather low (typically at the levels of $\mathrm{fmol} / \mathrm{ml}$ ) and difficult to quantify precisely. Available data regarding hemolymph MIH titers throughout the molt cycle are limited to three species, $C$. maenas, C. sapidus, and P. clarkii (197-199). Data in line with this hypothesis mainly come from the variation of $\mathrm{MIH}$ transcript levels throughout the molt cycle. In C. sapidus, $L$. vannamei, M. nipponense, and Scylla paramamosain, $\mathrm{MIH}$ transcript levels were relatively high during the inter-molt stage (stage C), declined gradually in the pre-molt stage (stage $D)$, and then returned to a level similar to that of the inter-molt after molting (stage A/B) $(111,132,200,201)$. The hemolymph ecdysteroid levels in C. sapidus and L. vannamei displayed a corresponding elevation during pre-molt stage when mih gene expression was low $(111,200)$. Unexpectedly, a significant drop in hemolymph MIH levels was observed only in P. clarkii (197), whereas those in C. maenas and C. sapidus remained unchanged during pre-molt stage $(198,199)$, which contradict the proposed hypothesis. Thus, the model is considered to be incomplete, mainly because the absence of the pre-molt drop in MIH levels, at least in certain species, is not accounted for. In this regard, Chung and Webster first noted that the effect of MIH on the Yorgan of C. maenas is molt stage-dependent. The inhibitory effect of $\mathrm{MIH}$ on ecdysteroidogenesis was the highest ( $60 \%)$ during inter-molt stage. The effect then dropped significantly during pre-molt and post-molt stages (less than 10\%), indicating that the Y-organ became refractory to MIH stimuli at these stages (185). Similar observations were also reported in P. clarkii that $\mathrm{MIH}$ significantly inhibited ecdysteroidogenesis during intermolt stage $(\sim 80 \%)$, and this inhibitory effect became much weaker (less than $10 \%$ ) during the middle-premolt stage (192, 202). Pharmacological studies showed that the activity of phosphodiesterase 1 (PDE1), a calcium/calmodulin-activated $\mathrm{PDE}$ isoform, is closely related to the decreased responsiveness of the Y-organ to the inhibition by MIH during the pre-molt stage (192).

Regardless of the inconsistencies in the results obtained from different species, silencing of MIH expression utilizing $\mathrm{MIH}$ dsRNA resulted in a significant acceleration of molt frequencies $(132,203,204)$ and elevation of ecdysteroids in the hemolymph (203), indicating a definite role of $\mathrm{MIH}$ in the regulation of crustacean molting and growth.

\section{Stimulation of Vitellogenesis by MIH}

Vitellogenin $(\mathrm{Vg})$, the precursor of vitellin, is synthesized in the ovaries, hepatopancreas, or both (205-207). It is cleaved into smaller subunits in the hemolymph, and then stored as vitellin in growing oocytes $(208,209)$. Therefore, levels of $v g$ transcripts in target tissues and $\mathrm{Vg}$ in hemolymph are commonly used as indicators of the progression of female reproduction in crustaceans (210). More recently, a novel function of $\mathrm{MIH}$ in stimulating ovarian growth via inducing vitellogenesis has been reported in a few species. In C. sapidus, MIH is capable of inducing hepatopancreatic $v g$ mRNA expression and $\mathrm{Vg}$ secretion at mid-vitellogenesis stage (211). The hemolymph $\mathrm{MIH}$ titers in female crab were about four-times higher at the mid-vitellogenesis stage than those at the pre-vitellogenesis stage. Additionally, MIH-specific binding sites have been identified on hepatopancreas membrane preparations (194), indicating that $\mathrm{MIH}$ might act directly on the hepatopancreas to increase $\mathrm{Vg}$ production. Interestingly, the number of MIH binding sites on the hepatopancreas of adult females shows an "ovarian stagedependent" variation that is two-times higher at the midvitellogenesis stage than at the pre-vitellogenesis or early vitellogenesis stage (194). Similar findings were also reported in Metapenaeus ensis and L. vannamei in that one of the two $\mathrm{MIH}$ isoforms of each species (namely, MeMIH-B and LivMIH2) stimulated vitellogenesis and promoted ovarian growth. In vitro incubation of ovarian explants and/or hepatopancreas with recombinant $\mathrm{MIH}$ resulted in the upregulation of $v g$ transcript levels in M. ensis and L. vannamei (114, 212). Injection of recombinant $\mathrm{MIH}$ increased $\mathrm{Vg}$ content in both hemolymph and the ovary in $M$. ensis and induced ovarian maturation in L. vannamei. Additionally, injection of dsRNA also reduces MeMIH-B transcript levels in the hepatopancreas and ovary, resulting in lower $\mathrm{Vg}$ levels in the hemolymph. These combined data demonstrate a stimulatory role for $\mathrm{MIH}$ on female reproduction $(114,194,211,212)$. Regarding crabs with a reproductive phase accompanied by a terminal anecdysis, Zmora et al. (211) concluded that MIH is a vital regulator coordinating the reciprocal antagonism of molt and reproduction by keeping animals at an anecdysial status and stimulating vitellogenesis when the animals are sexually maturing.

\section{Inhibition of Ovarian Maturation by GIH}

GIH is another member in the Type-II group. After its first identification in $H$. americanus (25), GIH has been identified in several other species mainly through molecular cloning (213-216). 
Recombinant GIH decreased in vitro vg transcript levels in the ovary (216) and GIH dsRNA decreased $v g$ transcript levels in the ovary of $P$. monodon and the hepatopancreas of L. vannamei (215, 216). A single injection of GIH dsRNA was capable of suppressing gih expression for at least 30 days, leading to ovarian maturation and spawning in P. monodon (217).

\section{Inhibition of Methyl Farnesoate Synthesis by MOIH}

Methyl farnesoate (MF), the sesquiterpenoid structurally related to insect juvenile hormone III (218), is a secretory product of the mandibular organ which participates in controlling growth and reproduction in crustaceans (219-222). The existence of an inhibitory factor that negatively regulates MF synthesis was proposed based on the observation that eyestalk ablation caused an increase in hemolymph MF levels in the hemolymph (223), while injection of eyestalk extract reversed the effect of eyestalk ablation (224).

In C. pagurus, two MOIHs (MOIH-1 and MOIH-2), which suppressed MF synthesis in vitro, have been purified from the sinus gland extract and characterized. MOIH-1 and MOIH-2, unblocked at both ends, exhibits significant sequence similarity with MIHs (26). Their gene structure and sequence similarity indicated that the moih and mih genes arose by divergence following a gene duplication event (118). An interesting issue regarding MOIH is the apparently restricted existence of MOIHs in the cancrid crabs (225), suggesting that the gene duplication event was relatively recent, probably not earlier than the divergence of the Cancer genus (118). In some non-cancrid brachyurans (L. emarginata and C. maenas), $\mathrm{CHH}$ inhibits $\mathrm{MF}$ synthesis (186, 226), probably assuming the role of $\mathrm{MOIH}$, whereas in C. pagurus, functionally and structurally distinct $\mathrm{CHH}$ and $\mathrm{MOIH}$ are present (26). Whether moih genes are present and expressed in other brachyuran taxa is unknown.

\section{PEPTIDE STRUCTURE, SIGNAL TRANSDUCTION PATHWAYS, AND RECEPTORS}

\section{Peptide Structure}

The first structural model of the $\mathrm{CHH}$ superfamily peptide was that of MIH (Pej-MIH) from M. japonicus resolved by nuclear magnetic resonance (NMR) spectroscopy. It consists of a long Nterminal tail, followed by five alpha helices $(\alpha 1-\alpha 5)$, and a Cterminal tail (92). Subsequently, two more structures of the crustacean member peptides have been elucidated: Pej-SGP-IGly, the glycine-extended precursor of a $M$. japonicus $\mathrm{CHH}$ by X-ray crystallography (91), and Sco-CHH-L, the CHH-L from the pericardial organ of $S$. olivacea by NMR spectroscopy (Protein Data Bank: 5XS1). Although topologically equivalent helices- $\alpha 2, \alpha 3$, and $\alpha 4$ ( $\pi 4$ in Sco-CHH-L)-are present in the core of the three structures, Pej-MIH and Sco-CHH-L are more topologically resemble one another than Pej-SGP-I-Gly (Figure 3). Thus, Pej-MIH and Sco-CHH-L additionally have a topologically similar C-terminal $\alpha 5$, which brings the C- and
N-terminal ends sterically close each other (Figure 3). In contrast, Pej-SGP-I-Gly, which lacks an $\alpha 5$, has a relatively long $\alpha 4$ followed by a C-terminal tail that is kept away from the N-terminal end (Figure 3). Because of the limited availability of the C-terminal amidated Pej-CHH, Pej-SGP-I-Gly, a nonamidated precursor was used for structural determination (91). Post-translational amidation at the C-terminal increased the $\alpha$-helical content of $\mathrm{CHH}(139,140,172)$, indicating that the $\mathrm{C}$-terminal modification renders structural changes. Thus, while additional structures of the $\mathrm{CHH}$-superfamily peptides (e.g., amidated $\mathrm{CHH}$ and ITP) are needed for validation, it is likely that the folding pattern shared by Pej-MIH and Sco-CHH-L is a common theme for the crustacean and insect peptides of the superfamily. Functionally critical residues at the terminal regions of $\mathrm{MIH}, \mathrm{CHH}$, and ITP have been demonstrated using mutated recombinant peptides $(87-90,139,140,227)$. It is likely that parts of the structure, consisting of the sterically close C- and $\mathrm{N}$ terminal regions of the peptide, where the functionally critical residues are located, play important roles in forming the binding site for receptor interaction and activation.

\section{Signal Transduction Pathways and Receptors}

Radiolabeled peptides (125-I) have been used in several studies to identify the potential target tissues of $\mathrm{CHH}, \mathrm{MIH}$, or $\mathrm{CHH}-\mathrm{L}$ and to profile the binding characteristics of the presumed receptor $(86,193,228,229)$. Generally, each of the crustacean members of the superfamily binds to a distinct binding site (receptor) with high specificity. In the shore crab C. maenas, Yorgans clearly have separate and highly specific binding sites for $\mathrm{CHH}$ and MIH (193). Similarly, in the blue crab C. sapidus, displacement experiments in multiple tissues also revealed that $\mathrm{CHH}$ and $\mathrm{CHH}-\mathrm{L}$ peptide each has discrete specific binding sites (229). Another aspect of $\mathrm{CHH}$ binding specificity was illustrated by studies on hepatopancreas membranes from C. maenas and O. limosus (228). Membranes derived from C. maenas had a much lower affinity for $O$. limosus $\mathrm{CHH}$ than for $C$. maenas $\mathrm{CHH}$ (228), reflecting the species-specificity of $\mathrm{CHH}$ in terms of hyperglycemic activity (152).

A wealth of literature has been accumulated over the years regarding the signal transduction pathways of the $\mathrm{CHH}$ superfamily peptides, mostly concerning $\mathrm{MIH}, \mathrm{CHH}$, and ITP. These include studies in various species utilizing in vitro or in vivo assays with tissue preparations or hormones, cyclic nucleotide analogues, and pharmacological agents inhibiting or stimulating activity of enzymes involved in the signaling pathways. In general, the studies have concluded that cyclic adenosine monophosphate (cAMP), cyclic guanosine monophosphate (cGMP), or both act as intracellular signaling messengers mediating the action of the $\mathrm{CHH}$-superfamily peptides. However, experimental data are in several instances inconsistent and contradictory, particularly for studies involving MIH. Until recently, the nature (receptor guanylyl cyclase vs. adenylyl cyclase-activating $G$ protein-coupled receptor) of the putative receptor for the $\mathrm{CHH}$-superfamily peptides were only speculated upon based on data derived from the early studies. In 
a more recent study of the silkworm B. mori, orphan $G$ proteincoupled receptors (GPCRs) were determined to be receptors for ITPs (ITP and ITP-L peptides), the characterization of which provided data for building a model of the signaling transduction pathway of ITPs (94), which is in general similar to an earlier one suggested for MIH (230).

\section{CHH and CHH-L}

Early studies investigating $\mathrm{CHH}$ signal transduction pathways implicated both cyclic nucleotides as second messengers mediating the action of the hormone $(156,157)$. Thus, $\mathrm{CHH}$ preparations increased cGMP and cAMP levels in vivo in several target tissues, including the hepatopancreas and muscle of the crayfish, O. limosus. In in vitro incubations of the hepatopancreas, cGMP levels were significantly increased by $\mathrm{CHH}$, which was followed by release of glucose into the tissue incubation media, whereas cAMP levels were already elevated during the incubation and not further increased by hormonal treatment (156). Further, injection of $\mathrm{CHH}$ into the eyestalk-ablated crayfish increased cGMP and cAMP levels and decreased glycogen synthase activity in the abdominal muscle. Cyclic nucleotide analogues mimicked the effect of $\mathrm{CHH}$ preparations in inhibiting synthase activity (157). In $M$. japonicus, bilateral eyestalk ablation decreased intracellular cGMP levels of the hepatopancreas, with little effect on cAMP levels; corroboratively, exposure of tissues to recombinant $\mathrm{CHH}$ significantly increased the levels of cGMP, but not those of cAMP (231). The CHH-induced increase in cGMP levels in the muscle of $H$. americanus (232) was due to stimulation of the membranebound guanylyl cyclase (mGC), as cGMP increased not only in intact tissue but also in the isolated membrane preparations (233). Involvement of soluble GC (sGC) in the $\mathrm{CHH}$-induced cGMP increase was considered unlikely, as cytoplasmic sGC activity was not stimulated by $\mathrm{CHH}$ and the $\mathrm{CHH}$-induced cGMP increase was not blocked by methylene blue, an inhibitor of the nitric oxide (NO)-activated sGC (233). These combined results favor a scenario in which $\mathrm{CHH}$ binds and activates an mGC, thus elevating intracellular levels of cGMP as a second messenger, while changes in cAMP, if present, could occur downstream to receptor activation and cGMP elevation. An mGC (PcGC-M2), which was identified by cDNA cloning in the muscle of $P$. clarkii, was found to contain the signature domains characteristic of receptor GC (rGC), including an extracellular ligand-binding domain, a single transmembrane domain, and intracellular kinase-like and cyclase catalytic domains (234). PcGC-M2 is widely expressed in several target tissues of $\mathrm{CHH}$ (234), although the binding ligand for PcGC-M2 has not yet been determined.

The signaling pathway activated by CHH-L is much less characterized. In the blue crab C. sapidus, CHH-L (pericardial organ-CHH) significantly increased cGMP production in several tissues including scaphognathites, heart, midgut, hindgut, and abdominal muscles (229).

\section{MIH}

Results obtained from studies of the MIH-mediated suppression of ecdysteroidogenesis in the Y-organs in different species are often contradictory. On the one hand, cGMP was shown to be an important second messenger of MIH in several species, including O. limosus, C, sapidus, and P. clarkii. Thus, Y-organ incubated with native or recombinant $\mathrm{MIH}$ resulted in an increase of cGMP, but not cAMP, in these species $(192,202,235)$. In related experiments, cGMP invariably played a crucial role in the mediation of MIH action: a cGMP analogue (8-Br-cGMP) significantly suppressed ecdysteroid production by Y-organ of $C$. sapidus, but neither cAMP analogues (db-cAMP or 8-Br-cAMP) nor an activator of adenylyl cyclase (forskolin) had a detectable effect on ecdysteroidogenesis (236); addition of synthetic MIH to the incubation medium increased cGMP levels, but not cAMP levels, in P. clarkii Y-organs (192). Corroborative observations were also reported for $C$. maenas Y-organ in which treatment with purified $\mathrm{MIH}$ produced a large and sustained increase in intracellular cGMP levels (237). These results are consistent with a model in which cGMP functions as a second messenger in the cellular action of $\mathrm{MIH}$ and that the receptor for MIH is likely a rGC. On the other hand, studies in Cancer antennarius showed that adding eyestalk extract (which contains a wide variety of bioactive compounds, including $\mathrm{MIH}$ ) to incubation of Y-organs resulted in an increase in cAMP levels (189). Additionally, dbcAMP and agents (forskolin and choleragen) that increased intracellular cAMP, each mimicked the inhibitory action of $\mathrm{MIH}$, while 3',5'-cGMP did not. It was thus concluded that cAMP mediates MIH-induced suppression of ecdysteroid production (189).

Data supporting the notion that the MIH receptor is an mGC and that cGMP functions as a second messenger were obtained in follow-up studies in C. sapidus. Thus, a cDNA (CsGC-YO1) encoding an rGC was cloned from C. sapidus Y-organ (238). Immunohistochemical staining using a primary antibody raised against the extracellular domain showed that CsGC-YO1 is located on the Y-organ cell membrane. Y-organ preconditioned with the anti-extracellular domain antibody became refractory to the stimulation of $\mathrm{MIH}$. In addition, sodium nitroprusside (an NO donor) failed to inhibit ecdysteroidogenesis in Y-organ of $C$. sapidus, suggesting that $\mathrm{NO} / \mathrm{sGC/cGMP}$ signaling pathway is not involved in the MIH action (196). Finally, the transcript levels of CsGC-YO1 in Y-organ of the inter-molt animals were four- and two-times higher than those in the pre-molt and post-molt $\mathrm{Y}$ organs, respectively (239).

Alternatively, a model hypothesizing that the $\mathrm{MIH}$ receptor is a G protein-coupled receptor (GPCR) was proposed (230) based on data obtained mainly from the crab Gecarcinus lateralis (240-243). In combination with previous related studies $(230,243)$ and the transcriptomic analysis, the G. lateralis Y-organ was proposed to go through a four-stage transition (basal, activated, committed, and repressed stages) from inter-molt (stage $\mathrm{C}_{4}$ ), early pre-molt (stage $\mathrm{D}_{0}$ ), middle pre-molt (stage $\mathrm{D}_{1}, \mathrm{D}_{2}$ ) and late pre-molt stage (stage $\left.\mathrm{D}_{4}\right)$, respectively $(244,245)$. The $\mathrm{MIH}$ signaling pathway plays a dominant role in the inter-molt and early pre-molt stage to suppress ecdysteroid production. According to the model, ligand activation of $\mathrm{MIH}$ receptor leads to, via a G protein, stimulation of adenylyl cyclase and subsequent cAMP-protein kinase A (PKA) pathway. Phosphorylation of enzymes by PKA in turn causes inhibition of ecdysteroidogenesis. Another phosphorylation event activated by 
PKA leads to an increase in membrane calcium conductance, resulting in $\mathrm{Ca}^{2+}$ influx that activates NO-sensitive sGC pathways through $\mathrm{Ca}^{2+} /$ calmodulin activation of nitric oxide synthase. Increase in cGMP levels and subsequent activation of protein kinase G ultimately lead to inhibition of ecdysteroidogenesis. This working hypothesis is sustained by a series of experimental studies. First, analysis of $G$. lateralis Y-organ transcriptome indicated the expression of signaling components mentioned above (including adenylyl cyclases, PKA, PKG, calmodulin, NOS, NO-sensitive guanylyl cyclase (GC-I), and GPCRs) (95, 121, 246). Second, the production of ecdysteroids in vitro was repressed by NO donors (SNAP and SE175) and by cAMP and cGMP analogues $(247,248)$. Third, an adenylyl cyclase (AC) activator (forskolin) inhibited the production of ecdysteroids (248). Fourth, in combination with IBMX, an sGC activator (YC-1) inhibited ecdysteroid secretion in Y-organ (247). Finally, eyestalk ablation led to the up-regulation of NO-independent-NOS, GC-I, and GC-III mRNA levels, causing the Y-organ to be more sensitive to $\mathrm{MIH}$ stimuli, presumably a compensatory response to the removal of MIH (240).

\section{GIH and MOIH}

Information about GIH and MOIH signaling cascades are still limited. Effects of various pharmacological reagents have been tested in an in vitro assay using $\mathrm{vg}$ mRNA expression in ovarian explants from M. japonicus (249). Results showed that db-cAMP, db-cGMP, forskolin, and IBMX mimicked the inhibitory effects of GIH in reducing the levels of $v g$ mRNA in a dose-dependent manner. Similar results were also obtained when A23187 (calcium ionophore) and PMA (an activator of protein kinase C) were added into the incubation medium. These results suggested that cyclic nucleotides, calcium, and protein kinase $\mathrm{C}$ are involved in regulating Vg transcription in the ovary (249). However, whether these signaling components were coupled to GIH activation has not been determined. Recently, a study on the mode of GIH action was carried out in L. vannamei using $v g$ expression in the hepatopancreas as the bioassay. According to Chen et al. (250), in vivo injection and in vitro incubation of hepatopancreatic primary cells with recombinant GIH elevated the levels of intracellular cGMP, but not cAMP or nitric oxide, indicating that GIH exerts a cGMP-mediated inhibitory action. Pharmacological reagents were then tested to characterize the GIH signaling pathway. Results showed that GIH employs an $\mathrm{rGC/cGMP/PKG} \mathrm{signaling} \mathrm{pathway}$ in inhibiting $v g$ expression; phosphorylation of c-Jun N-terminal kinases and upregulation of expression of p38MAPK (a mitogenactivated protein kinase) were implicated as signaling events downstream to PKG activation.

For $\mathrm{MOIH}$, the only result has come from a study of C. pagurus, in which an increase in CAMP was observed with hormonal treatment and with CAMP analogues that mimicked the action of MOIH, implying cAMP as a second messenger for MOIH (251).

\section{ITP/ITP-L}

cAMP, cGMP, and agents that increase cAMP levels individually were able to mimic the effect of ITP on ileal short-circuit current. Additionally, synthetic ITP elevated intracellular levels of both cyclic nucleotides in a dose-dependent manner $(36,252)$, again implying the involvement of these two cyclic nucleotides in ITP signal transduction. Importantly, receptors of ITP and ITP-L peptides have recently been identified and characterized in the silkworm B. mori (94). B. mori orphan neuropeptide G proteincoupled receptors (BNGRs), obtained through in silico mining of the silkworm genome, were screened using a $\mathrm{Ca}^{2+}$-imaging for activation by recombinant ITP and ITP-L peptides in HEK293T cells co-expressing a BNGR and a promiscuous mouse $\mathrm{G}_{\alpha 15}$. Out of the 34 BNGRs tested, three Class-A BNGRs reacted positively to activation by ITPs, with BNGR-A2 and -A34 responding to ITP (EC ${ }_{50}: 1.1 \times 10^{-8} \mathrm{M}$ and $1.3 \times 10^{-8} \mathrm{M}$, respectively) and BNGR-A24 to ITP-L (EC $\left.50: 2.6 \times 10^{-8} \mathrm{M}\right)$. Interaction between ITPs and BNGRs was evaluated by an in vitro assay that showed co-localization of the ligand and BNGR at the cell membrane of $\mathrm{CHO}$ cells heterologously expressing the receptor; the interaction occurred in a ligand-receptor-specific manner, consistent with the data for the distinct receptor responses to ligand activation observed using $\mathrm{Ca}^{2+}$ imaging. Stimulation of B. mori ovaryderived $(\mathrm{BmN})$ cells by either ITP or ITP-L significantly increased the intracellular cGMP levels. Coupling of the BNGRs to the ITPs-induced cGMP signaling was demonstrated by observations that simultaneous knockdown of bngr-A2 and -A34 significantly decreased the cGMP response to ITP in BmN cells, whereas knockdown of bngr-A24 led to decreased cGMP responses to ITP-L; transient expression of $b n g r-A 24$ potentiated the response of BmN cells to ITP-L. The involvement of $\mathrm{mGC}$ and sGC in the signaling of ITPs was examined in BmN cells using, respectively, dsRNA targeting BmGyc76c (a B. mori mGC) or ODQ (a selective and potent inhibitor of NO-sensitive sGC), showing that both GC forms are involved in signaling via ITPs through cGMP production (94). A model for the signaling pathway of ITPs in BmN cells was proposed (94), which is in general similar to the MIH model proposed by Chang and Mykles (230), except that it includes the involvement of both mGC and sGC (Figure 5). Thus, activation of BNGR receptors by their respective ligands leads to activation of adenylyl cyclase via Gprotein coupling and to activation of mGC. Like the MIH model, one of the events downstream to activation of protein kinase $\mathrm{A}$ activation is the increase in membrane calcium conductance, leading to $\mathrm{Ca}^{2+}$ influx, which in turn stimulates NO-sensitive sGC by activating $\mathrm{Ca}^{2+}$-calmodulin-dependent $\mathrm{NO}$ synthase. Increases in cGMP levels, due to the actions of both mGC and sGC, then activates protein kinase $G$, which together with protein kinase $\mathrm{A}$, result in cellular responses (Figure 5).

Identification of receptor for insect ITPs not only represents an important breakthrough for insect studies but also provides an opportunity to identify the receptors for crustacean member peptides. Previous studies of molecular mass of the $\mathrm{CHH}$ - and MIH-binding proteins, respectively, in the hepatopancreas and Y-organ of $C$. sapidus and $M$. japonicus showed that the estimated values (51-70 $\mathrm{kDa})$ were within the molecular mass range of typical GPCRs $(194,195)$. Given the concept that the peptide ligands co-evolve with their receptors, phylogenetic analysis of the crustacean and insect GPCRs has been performed searching for the crustacean orthologs that are phylogenetically clustered with the receptor for insect ITPs. 


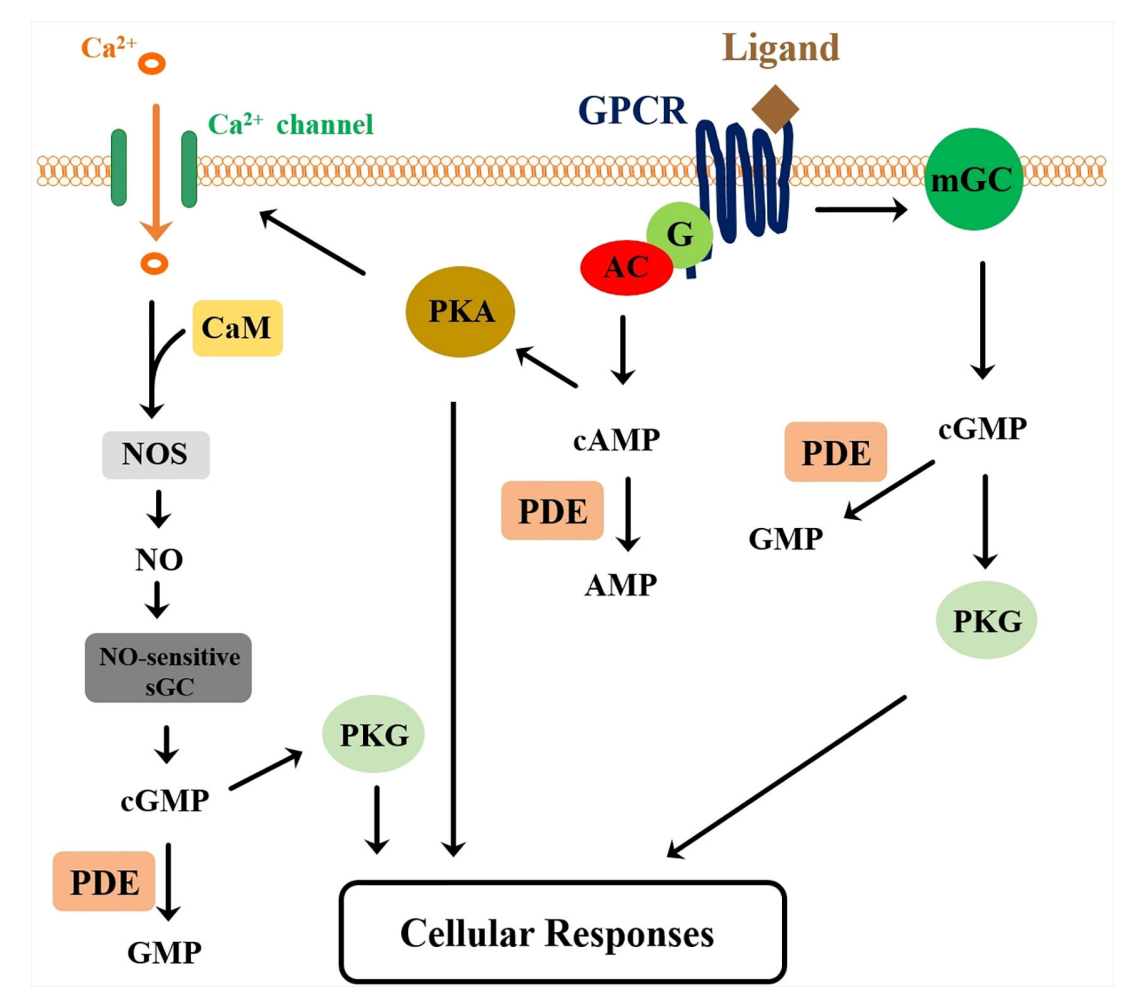

FIGURE 5 | A proposed signaling pathway for the crustacean and insect member peptides of the CHH-superfamily. A G protein-coupled receptor (GPCR) functions as the receptor for the peptide ligands. Ligand-receptor interaction leads to activation of the adenylyl cyclase (AC), via a coupling $G$ protein $(G)$, and of the membrane guanylyl cyclase ( $\mathrm{mGC}$ ), resulting respectively in the elevation of CAMP and cGMP levels. Activation of protein kinase A (PKA) by cAMP leads to the increase of intracellular $\mathrm{Ca}^{2+}$ levels, through phosphorylation of membrane calcium channel. $\mathrm{Ca}^{2+} /$ Calmodulin (CaM) complex stimulates nitric oxide synthase (NOS), increasing NO production, which in turn activates NO-sensitive soluble GC (sGC) for higher levels of cGMP production. Downstream events activated by the combined actions of PKA and PKG ultimately lead to cellular responses. Cyclic nucleotides are degraded by phosphodiesterases (PDEs). This model is a composite derived from Chang and Mykles (230) and Nagai et al. (94).

Thus, analysis of transcriptome data derived from $P$. clarkii tissues has uncovered GPCRs, Procambarus GPCRs A52, A53 and A63, that clustered with BNGR-A34, and Procambarus GPCR A9 with BNGR-A24, with A52 and A63 being abundantly expressed in the hepatopancreas, implying these GPCRs could be the crayfish $\mathrm{CHH}, \mathrm{MIH}$, or $\mathrm{CHH}-\mathrm{L}$ receptor (97). In addition, analysis of the data derived from the spiny lobster Sagmariasus verreauxi revealed 2 annotated GPCRs (SvGPCRA11 and 12) that are phylogenetically clustered with BNGR-A34 (96). In the blackback land crab G. lateralis Y organ transcriptome 3 GPCRs (Gl-GPCRA9, Gl-GPCRA10, Gl-GPCRA12) were similarly identified using phylogenetic analysis as potential $\mathrm{CHH}$-like receptors, as these sequences clustered into the putative $\mathrm{CHH}$ receptors clade (95). Expression of one of the GPCRs, Gl-GPCRA12, decreased in late pre-molt and post-molt stages, suggesting that it may be the $\mathrm{MIH}$ receptor (95). These results are promising and provide receptor candidates for testing of ligand binding and receptor activation to truly establishing the status of these receptors for the crustacean peptides.

The signaling model based on experimental data mainly derived from the studies of $G$. lateralis and B. mori $(94,230)$ is attracting and probably applicable to the crustacean and insect members of the $\mathrm{CHH}$ superfamily (Figure 5). Several major coupling events however need experimental verification, including coupling of GPCR activation to adenylyl cyclase, GPCR activation of membrane GC (as suggested in the ITPs signaling), PKA phosphorylation-induced $\mathrm{Ca}^{2+}$ influx and subsequent NO production. In addition, for the model to be applicable to the crustacean $\mathrm{CHH}$-superfamily peptides, including $\mathrm{CHH}$, the model would have to be refined, based on data from additional studies, to accommodate the apparently contradictory data derived from other studies. For example, in response to hormonal stimulation, the change in cAMP levels was usually small and insignificant $(192,235,237)$ and manipulation of cAMP levels or adenylyl cyclase activity did not mimic the effect of hormonal treatment (192). Further, it is interesting note that the lobster $\mathrm{CHH}$ stimulated the guanylyl cyclase activity in isolated membrane (233). Thus, GPCR activation of $\mathrm{mGC}$ would occur within the membrane without signaling through the cytoplasm. A GPCR-activated mGC event within the membranes, if proven, would probably represent a novel mode of GPCR signaling mechanism. Finally, it is now feasible to conduct experiments for ligand-receptor interaction 
and activation, with the availability of identified receptors and of information regarding ligand structure and structure-function relationship of several peptides, including $\mathrm{MIH}, \mathrm{CHH}, \mathrm{CHH}-\mathrm{L}$, ITP (87-93).

\section{CONCLUSION AND PROSPECTIVE DEVELOPMENTS}

The field of study of the $\mathrm{CHH}$ superfamily is now at a challenging and promising phase. With more research efforts, most likely through mining newly available genomes and transcriptomes from additional ecdysozoan taxa, it is certain that new members of the superfamily will be discovered. The phylogenetic profile would be updated as new members are admitted to the superfamily. The fact remains that the study of crustaceans suffers, at least at the level of the malacostracans, and in comparison with hexapods, from genomes of often enormous size, which constitutes an obstacle in technical as well as financial terms. The hypothetical multiplication of genomes of these taxa has certainly actively promoted diversity with the appearance of paralogues and processes of sub-functionalization.

Evolutionary recruitment of the $\mathrm{CHH}$-superfamily peptides as venom toxins (43) elegantly illustrates how changes in the structural characteristics of the peptides during the course of evolution has led to the emergence of novel functions, which indeed carries significant implications for the structure-function relationships of the crustacean member peptides. In this context, we could also question the fact that, in crustaceans where isoforms of the superfamily members are the most numerous, no venomous forms have yet been identified (except for the remipede Speleonectes tulumensis (253) that has toxins unrelated to the $\mathrm{CHH}$ superfamily), whereas this is the case in other major arthropod phyla. On the other hand, post-transcriptional and post-translational mechanisms that are well known for structurally and functionally diversifying the superfamily peptides are expected (and have actually been suggested by recent studies) to be also working on the venom peptide-encoding genes and the peptides. We likely will see more instances where results gained from the study of one group of peptides of the superfamily "complement" or "echo" those from studies of others.

While the crustacean and insect member peptides of the $\mathrm{CHH}$ superfamily have been characterized and identified, each with a distinct functional assay, progress in the functional front has been limited, if compared to the number of publications devoted to identification of the peptides and genes. Technical resources are essential for functional studies. Recombinant protein production, RNAi, and various functional genomics methods are now readily available and have indeed been widely used by researchers in the field. In this context, one particular technical obstacle for the study of $\mathrm{CHH}$ and ITP is the limited availability of biologically active peptides, production of which usually relies on costly and tedious modifications (e.g., the C-terminal amidation) and refolding of bacterially-produced peptides. The obstacle becomes almost prohibitively challenging for structural studies that require large amounts of peptide. Alternatives, e.g., chemical synthesis $(133,254)$ and eukaryotic expression systems $(88,255)$, could be explored to optimize the production of biologically active peptides at larger scales. Advancements in the functional front are expected if more research efforts are to be made. A persuasive example is a sophisticated model for the regulation of steroidogenesis in the Y-organ built mainly based upon functional genomics data [see (245)]. Additional genetic resources enjoyed by the study of insects, especially those working in the fruit fly D. melanogaster, as exemplified by a study of ITP (174), would probably render a faster development for the study of insect member peptides. On the application side, initial attempts were made in developing methods for manipulation of ovarian maturation and control of viral diseases respectively through silencing of gih and chh genes by RNAi $(179,217)$, a technical approach that has been put to practical use in aquaculture industry in the case of manipulating a crustacean insulin-like androgenic gland hormone (256).

Functional studies would be greatly aided by the identification of receptors for the superfamily peptides, which was finally realized by the discovery of the receptors for the silkworm ITPs (94). Crustacean orthologues of the silkworm ITP receptors were suggested to be the receptors for the crustacean member peptides (95-97). The pressing issue would be to provide experimental data testing whether the ligands bind and activate the candidate receptors. With the receptor for the peptides being identified, confirmation of the target tissues of a given peptide and the signal transduction pathways coupled to receptor activation could be examined. Interesting and physiologically relevant questions could be asked, for instance, regarding a function shared by two superfamily peptides (functional overlap) or a multi-functional (pleiotropic) peptide. For example, whether the Y-organ cells express both $\mathrm{MIH}$ and $\mathrm{CHH}$ receptors, as suggested by the radiolabeled-ligand binding experiments? How are the respective signaling pathways activated by $\mathrm{MIH}$ and $\mathrm{CHH}$ orchestrated in regulating steroidogenesis in the Y-organ? The prospective developments for the functional study of the $\mathrm{CHH}$ superfamily in a post-receptor era are promising and the discoveries to be made will certainly be rewarding!

\section{AUTHOR CONTRIBUTIONS}

Writing: H-YC, J-YT, and C-YL. Coordination: C-YL.

\section{ACKNOWLEDGMENTS}

The authors thank Céline Ollivaux (Sorbonne Université, France) for providing the images used in Figure 2, and Yun-Ru Chen (Academia Sinica Protein Clinic) and Syuan-Huai Shih (National Changhua University of Education) for preparing Figures 3 and 4, respectively. Special thanks are due to Kurt Liittschwager for editing an early version of the manuscript. Financial support from the Ministry of Science and Technology (107-2311-B-018-001, 108-2311-B-018-001) to C-YL and from Ministry of Education through National Penghu University of Science and Technology (107G0049, 108G0038) to H-YC is acknowledged. 


\section{REFERENCES}

1. Koller G. Farbwechsel bei Crangon vulgaris. Verh Dtsch Zool Ges (1925) 30:128-32.

2. Koller G. Uber Chromatophorensystem, Farbensinn und Farbwechsel bei Crangon vulgaris. Z Vergleichende Physiol (1927) 5:192-246.

3. Koller G. Versuche uber die inkretorischen Vorgang beim Garneelenfarbwechsel. Z Vergl Physiol (1928) 8:601-12.

4. Perkins E. Color changes in crustaceans, especially in. PalaemonetesJ Exp Zool (1928) 50:71-105.

5. Courrier R. Sur le determinisme des caracteres sexuels secondaires chez les Arthropodes. CR Hebd Acad Sci (1921) 173:668-71.

6. Megušar F. Experimente uber den Farbwechsel der Crustaceen (I: Gelasimus. II: Potamobius. III. Palaemonetes IV: Palaemon) Dev Genes Evol (1912) 33:462-665.

7. Zeleny C. The regulation of the degree of injury to the rate of regeneration. J Exp Zool (1905) 2:347-69.

8. Hopkins PM. The eyes have it: A brief history of crustacean neuroendocrinology. Gen Comp Endocrinol (2012) 175:357-66.

9. Fingerman M. Crustacean endocrinology: A retrospective, prospective, and introspective analysis. Physiol Zool (1997) 70:257-69.

10. Kleinholz LH. Crustacean neurosecretory hormones and physiological specificity. Am Zoologist (1976) 16:151-66.

11. Hanström B. Die Sinusdrfise und der hormonal bedingte Farbwechsel der Crustaceen. Kunglica Sven V etenskapsakademiens Handlingar 3d Ser (1937) 16:1-99.

12. Welsh J. New evidence concerning the source and action of the eyestalk hormone. Anat Rec (1951) 111:442.

13. Passano LM. The $\mathrm{X}$ organ-sinus gland neurosecretory system in crabs. Anat $\operatorname{Rec}(1951)$ 111:502.

14. Passano LM. The X organ, a neurosecretory gland controlling molting in crabs. Anat Rec (1951) 111:559.

15. Bliss DE. Metabolic effects of sinus gland or eyestalk removal in the land crab. Gecarcinulsa teralisAnat Rec (1951) 111:502-3.

16. Brown FA. The crustacean sinus gland and chromatophore activation. Physiol Zool (1940) 13:343-55.

17. Hanström B. Neue Untersuchungen uber Sinnesorgane und Nervensystem der Crustaceen, II. Zool Jahrb Abt Allg Zool Physiol Tiere (1933) 56:387-520.

18. Carlisle DB, Passano LM. The X-organ of Crustacea. Nature (1953) 172:404-5.

19. Kegel G, Reichwein B, Tensen CP, Keller R. Amino acid sequence of crustacean hyperglycemic hormone $(\mathrm{CHH})$ from the crayfish, Orconectes limosus: emergence of a novel neuropeptide family. Peptides (1991) 12:909-13.

20. Keller R. Crustacean neuropeptides: structures, functions and comparative aspects. Experientia (1992) 48:439-48.

21. Soyez D. Occurrence and diversity of neuropeptides from the crustacean hyperglycemic hormone family in arthropods. A short Rev Ann N Y Acad Sci (1997) 814:319-23.

22. Kegel G, Reichwein B, Weese S, Gaus G, Peter-Katalinic J, Keller R. Amino acid sequence of the crustacean hyperglycemic hormone $(\mathrm{CHH})$ from the shore crab, Carcinus maenas. FEBS Lett (1989) 255:10-4.

23. Chang ES, Prestwich GD, Bruce MJ. Amino acid sequence of a peptide with both molt-inhibiting and hyperglycemic activities in the lobster, Homarus americanus. Biochem Biophys Res Commun (1990) 171:818-26.

24. Webster SG. Amino acid sequence of putative moult-inhibiting hormone from the crab Carcinus maenas. Proc Biol Sci (1991) 244:247-52.

25. Soyez D, Lecaer JP, Noel PY, Rossier J. Primary structure of 2 isoforms of the vitellogenesis inhibiting hormone from the lobster. Homarus Americanus Neuropeptides (1991) 20:25-32.

26. Wainwright G, Webster SG, Wilkinson MC, Chung JS, Rees HH. Structure and significance of mandibular organ-inhibiting hormone in the crab, Cancer pagurus. Involvement in multihormonal regulation of growth and reproduction. J Biol Chem (1996) 271:12749-54.

27. Liu L, Laufer H. Isolation and characterization of sinus gland neuropeptides with both mandibular organ inhibiting and hyperglycemic effects from the spider crab Libinia emarginata. Arch. Insect Biochem Physiol (1996) 32:375-85.

28. Liu L, Laufer H, Gogarten PJ, Wang M. cDNA cloning of a mandibular organ inhibiting hormone from the spider crab Libinia emarginata. Invert Neurosci (1997) 3:199-204.
29. Gu PL, Chan SM. The shrimp hyperglycemic hormone-like neuropeptide is encoded by multiple copies of genes arranged in a cluster. FEBS Lett (1998) 441:397-403.

30. Chan SM, Gu PL, Chu KH, Tobe SS. Crustacean neuropeptide genes of the $\mathrm{CHH} / \mathrm{MIH} / \mathrm{GIH}$ family: implications from molecular studies. Gen Comp Endocrinol (2003) 134:214-9.

31. Montagné N, Desdevises Y, Soyez D, Toullec JY. Molecular evolution of the crustacean hyperglycemic hormone family in ecdysozoans. BMC Evol Biol (2010) 10:62.

32. De Kleijn DPV, VanHerp F. Molecular biology of neurohormone precursors in the eyestalk of Crustacea. Comp Biochem Physiol B (1995) 112:573-9.

33. Lacombe C, Greve P, Martin G. Overview on the sub-grouping of the crustacean hyperglycemic hormone family. Neuropeptides (1999) 33:71-80.

34. Chen SH, Lin CY, Kuo CM. In silico analysis of crustacean hyperglycemic hormone family. Mar Biotechnol (NY) (2005) 7:193-206.

35. Chang WH, Lai AG. Comparative genomic analysis of crustacean hyperglycemic hormone $(\mathrm{CHH})$ neuropeptide genes across diverse crustacean species. F1000Res (2018) 7:100.

36. Audsley N, Phillips JE. Stimulants of ileal salt transport in neuroendocrine system of the desert locust. Gen Comp Endocrinol (1990) 80:127-37.

37. Meredith J, Ring M, Macins A, Marschall J, Cheng NN, Theilmann D, et al. Locust ion transport peptide (ITP): primary structure, cDNA and expression in a baculovirus system. J Exp Biol (1996) 199:1053-61.

38. Audsley N, McIntosh C, Phillips JE. Isolation of a neuropeptide from locust corpus cardiacum which influences ileal transport. J Exp Biol (1992) 173:261-74.

39. Christie AE. Neuropeptide discovery in Ixodoidea: An in silico investigation using publicly accessible expressed sequence tags. Gen Comp Endocrinol (2008) 157:174-85.

40. Christie AE, Nolan DH, Ohno P, Hartline N, Lenz PH. Identification of chelicerate neuropeptides using bioinformatics of publicly accessible expressed sequence tags. Gen Comp Endocrinol (2011) 170:144-55.

41. Christie AE. In silico characterization of the neuropeptidome of the Western black widow spider Latrodectus hesperus. Gen Comp Endocrinol (2015) 210:63-80.

42. Yu N, Han C, Liu Z. In silico identification of the neuropeptidome of the pond wolf spider Pardosa pseudoannulata. Gen Comp Endocrinol (2020) 285:113271.

43. Undheim EA, Grimm LL, Low CF, Morgenstern D, Herzig V, Zobel-Thropp $\mathrm{P}$, et al. Weaponization of a hormone: Convergent recruitment of hyperglycemic hormone into the venom of arthropod predators. Structure (2015) 23:1283-92.

44. McCowan C, Garb JE. Recruitment and diversification of an ecdysozoan family of neuropeptide hormones for black widow spider venom expression. Gene (2014) 536:366-75.

45. Toullec JY, Corre E, Mandon P, Gonzalez-Aravena M, Ollivaux C, Lee CY. Characterization of the neuropeptidome of a Southern Ocean decapod, the Antarctic shrimp Chorismus antarcticus: Focusing on a new decapod ITPlike peptide belonging to the $\mathrm{CHH}$ peptide family. Gen Comp Endocrinol (2017) 252:60-78.

46. Phillips JE, Meredith J, Audsley N, Richardson N, Macins A, Ring M. Locust ion transport peptide (ITP): A putative hormone controlling water and ionic balance in terrestrial insects. Amer Zool (1998) 38:461-70.

47. Dircksen H, Bocking D, Heyn U, Mandel C, Chung JS, Baggerman G, et al. Crustacean hyperglycaemic hormone $(\mathrm{CHH})$-like peptides and $\mathrm{CHH}$ precursor-related peptides from pericardial organ neurosecretory cells in the shore crab, Carcinus maenas, are putatively spliced and modified products of multiple genes. Biochem J (2001) 356:159-70.

48. Chen SH, Lin CY, Kuo CM. Cloning of two crustacean hyperglycemic hormone isoforms in freshwater giant prawn (Macrobrachium rosenbergii): evidence of alternative splicing. Mar Biotechnol (NY) (2004) 6:83-94.

49. Dai L, Zitnan D, Adams ME. Strategic expression of ion transport peptide gene products in central and peripheral neurons of insects. J Comp Neurol (2007) 500:353-67.

50. Chung JS, Zmora N. Functional studies of crustacean hyperglycemic hormones (CHHs) of the blue crab, Callinectes sapidus - the expression and release of $\mathrm{CHH}$ in eyestalk and pericardial organ in response to environmental stress. FEBS J (2008) 275:693-704. 
51. Dircksen H, Tesfai LK, Albus C, Nassel DR. Ion transport peptide splice forms in central and peripheral neurons throughout postembryogenesis of. Drosophila MelanogasterJ Comp Neurol (2008) 509:23-41.

52. Dircksen H, Kahsai L, Albus C, Mandali M, Nassel D. Identified Drosophila ion transport peptide splice forms are differentially expressed in central and peripheral neurons throughout postembryogenesis. Comp Biochem Physiol A (2008) 150:S134-4.

53. Tsai KW, Chang SJ, Wu HJ, Shih HY, Chen CH, Lee CY. Molecular cloning and differential expression pattern of two structural variants of the crustacean hyperglycemic hormone family from the mud crab Scylla olivacea. Gen Comp Endocrinol (2008) 159:16-25.

54. Zheng JY, Chen HY, Choi CY, Roer RD, Watson RD. Molecular cloning of a putative crustacean hyperglycemic hormone $(\mathrm{CHH})$ isoform from extraeyestalk tissue of the blue crab (Callinectes sapidus), and determination of temporal and spatial patterns of $\mathrm{CHH}$ gene expression. Gen Comp Endocrinol (2010) 169:174-81.

55. Wu HJ, Tsai WS, Huang SY, Chen YJ, Chen YH, Hsieh YR, et al. Identification of the crustacean hyperglycemic hormone $(\mathrm{CHH})$ and $\mathrm{CHH}$-like peptides in the crayfish Procambarus clarkii and localization of functionally important regions of the CHH. Zoological Stud (2012) 51:288-97.

56. Webster SG, Keller R, Dircksen H. The CHH-superfamily of multifunctional peptide hormones controlling crustacean metabolism, osmoregulation, moulting, and reproduction. Gen Comp Endocrinol (2012) 175:217-33.

57. Dircksen H. Insect ion transport peptides are derived from alternatively spliced genes and differentially expressed in the central and peripheral nervous system. J Exp Biol (2009) 212:401-12.

58. Begum K, Li B, Beeman RW, Park Y. Functions of ion transport peptide and ion transport peptide-like in the red flour beetle Tribolium castaneum. Insect Biochem Mol Biol (2009) 39:717-25.

59. Yu B, Li DT, Wang SL, Xu HJ, Bao YY, Zhang CX. Ion transport peptide (ITP) regulates wing expansion and cuticle melanism in the brown planthopper, Nilaparvata lugens. Insect Mol Biol (2016) 25:778-87.

60. Sun D, Lv J, Gao B, Liu P, Li J. Crustacean hyperglycemic hormone of Portunus trituberculatus: evidence of alternative splicing and potential roles in osmoregulation. Cell Stress Chaperones (2019) 24:517-25.

61. Ollivaux C, Soyez D, Toullec JY. Biogenesis of D-amino acid containing peptides/proteins: where, when and how? J Pept Sci (2014) 20:595-612.

62. Serrano L, Grousset E, Charmantier G, Spanings-Pierrot C. Occurrence of Land D-crustacean hyperglycemic hormone isoforms in the eyestalk X-organ/ sinus gland complex during the ontogeny of the crayfish Astacus leptodactylus. J Histochem Cytochem (2004) 52:1129-40.

63. Serrano L, Blanvillain G, Soyez D, Charmantier G, Grousset E, Aujoulat F, et al. Putative involvement of crustacean hyperglycemic hormone isoforms in the neuroendocrine mediation of osmoregulation in the crayfish Astacus leptodactylus. J Exp Biol (2003) 206:979-88.

64. Aguilar MB, Soyez D, Falchetto R, Arnott D, Shabanowitz J, Hunt DF, et al. Amino acid sequence of the minor isomorph of the crustacean hyperglycemic hormone (CHH-II) of the Mexican crayfish Procambarus bouvieri (Ortmann): presence of a D-amino acid. Peptides (1995) 16:1375-83.

65. Yasuda A, Yasuda Y, Fujita T, Naya Y. Characterization of crustacean hyperglycemic hormone from the crayfish (Procambarus clarkii): multiplicity of molecular forms by stereoinversion and diverse functions. Gen Comp Endocrinol (1994) 95:387-98.

66. Soyez D, Vanherp F, Rossier J, Lecaer JP, Tensen CP, Lafont R. Evidence for a conformational polymorphism of invertebrate neurohormones - D-aminoacid residue in crustacean hyperglycemic peptides. J Biol Chem (1994) 269:18295-8.

67. Chang ES, Chang SA, Beltz BS, Kravitz EA. Crustacean hyperglycemic hormone in the lobster nervous system: localization and release from cells in the subesophageal ganglion and thoracic second roots. J Comp Neurol (1999) 414:50-6.

68. Chung JS, Dircksen H, Webster SG. A remarkable, precisely timed release of hyperglycemic hormone from endocrine cells in the gut is associated with ecdysis in the crab Carcinus maenas. Proc Natl Acad Sci U.S.A. (1999) 96:13103-7.

69. Gu PL, Tobe SS, Chow BK, Chu KH, He JG, Chan SM. Characterization of an additional molt inhibiting hormone-like neuropeptide from the shrimp Metapenaeus ensis. Peptides (2002) 23:1875-83.
70. Wu SH, Chen YJ, Huang SY, Tsai WS, Wu HJ, Hsu TT, et al. Demonstration of expression of a neuropeptide-encoding gene in crustacean hemocytes. Comp Biochem Physiol A Mol Integr Physiol (2012) 161:463-8.

71. Shi L, Li B, Zhou TT, Wang W, Chan SF. Functional and evolutionary implications from the molecular characterization of five spermatophore $\mathrm{CHH} / \mathrm{MIH} / \mathrm{GIH}$ genes in the shrimp Fenneropenaeus merguiensis. PloS One (2018) 13:e193375.

72. Kung PC, Wu SH, Nagaraju GP, Tsai WS, Lee CY. Crustacean hyperglycemic hormone precursor transcripts in the hemocytes of the crayfish Procambarus clarkii: novel sequence characteristics relating to gene splicing pattern and transcript stability. Gen Comp Endocrinol (2013) 186:80-4.

73. Drexler AL, Harris CC, dela Pena MG, Asuncion-Uchi M, Chung S, Webster $S$, et al. Molecular characterization and cell-specific expression of an ion transport peptide in the tobacco hornworm, Manduca sexta. Cell Tissue Res (2007) 329:391-408.

74. Dircksen H, Mandali A, Yoshii T, Strauss J, Helfrich-Forster C, Nassel DR. Differential neuronal expression of three Drosophila ion transport peptide splice forms indicate multiple functions of peptidergic neurons. Comp Biochem Physiol A (2009) 153A:S79-9.

75. Turner LM, Webster SG, Morris S. Roles of crustacean hyperglycaemic hormone in ionic and metabolic homeostasis in the Christmas Island blue crab, Discoplax celeste. J Exp Biol (2013) 216:1191-201.

76. Morris S, Postel U, Mrinalini LM, Palmer J, Webster SG. The adaptive significance of crustacean hyperglycaemic hormone $(\mathrm{CHH})$ in daily and seasonal migratory activities of the Christmas Island red crab Gecarcoidea natalis. J Exp Biol (2010) 213:3062-73.

77. Li W, Chiu KH, Lee CY. Regulation of amino acid and nucleotide metabolism by crustacean hyperglycemic hormone in the muscle and hepatopancreas of the crayfish Procambarus clarkii. PloS One (2019) 14: e0221745.

78. Li W, Chiu KH, Tien YC, Tsai SF, Shih LJ, Lee CH, et al. Differential effects of silencing crustacean hyperglycemic hormone gene expression on the metabolic profiles of the muscle and hepatopancreas in the crayfish Procambarus clarkii. PloS One (2017) 12:e0172557.

79. Lin LJ, Chen YJ, Chang YS, Lee CY. Neuroendocrine responses of a crustacean host to viral infection: effects of infection of white spot syndrome virus on the expression and release of crustacean hyperglycemic hormone in the crayfish Procambarus clarkii. Comp Biochem Physiol A Mol Integr Physiol (2013) 164:327-32.

80. Lorenzon S, Edomi P, Giulianini PG, Mettulio R, Ferrero EA. Variation of crustacean hyperglycemic hormone $(\mathrm{cHH})$ level in the eyestalk and haemolymph of the shrimp Palaemon elegans following stress. J Exp Biol (2004) 207:4205-13.

81. Stentiford GD, Chang ES, Chang SA, Neil DM. Carbohydrate dynamics and the crustacean hyperglycemic hormone $(\mathrm{CHH})$ : effects of parasitic infection in Norway lobsters (Nephrops norvegicus). Gen Comp Endocrinol (2001) 121:13-22.

82. Wanlem S, Supamattaya K, Tantikitti C, Prasertsan P, Graidist P. Expression and applications of recombinant crustacean hyperglycemic hormone from eyestalks of white shrimp (Litopenaeus vannamei) against bacterial infection. Fish Shellfish Immunol (2011) 30:877-85.

83. Xu L, Pan L, Zhang X, Wei C. Crustacean hyperglycemic hormone (CHH) affects hemocyte intracellular signaling pathways to regulate exocytosis and immune response in white shrimp Litopenaeus vannamei. Peptides (2019) 116:30-41

84. Wang L, Chen H, Xu J, Xu Q, Wang M, Zhao D, et al. Crustacean hyperglycemic hormones directly modulate the immune response of hemocytes in shrimp Litopenaeus vannamei. Fish Shellfish Immunol (2017) 62:164-74.

85. Prymaczok NC, Pasqualino VM, Viau VE, Rodriguez EM, Medesani DA. Involvement of the crustacean hyperglycemic hormone $(\mathrm{CHH})$ in the physiological compensation of the freshwater crayfish Cherax quadricarinatus to low temperature and high salinity stress. J Comp Physiol B (2016) 186:181-91.

86. Chung JS, Webster SG. Binding sites of crustacean hyperglycemic hormone and its second messengers on gills and hindgut of the green shore crab, Carcinus maenas: a possible osmoregulatory role. Gen Comp Endocrinol (2006) 147:206-13. 
87. Liu CJ, Huang SS, Toullec JY, Chang CY, Chen YR, Huang WS, et al. Functional assessment of residues in the amino- and carboxyl-termini of crustacean hyperglycemic hormone ( $\mathrm{CHH})$ in the mud Crab Scylla olivacea using point-mutated peptides. PloS One (2015) 10:e0134983.

88. Zhao Y, Meredith J, Brock HW, Phillips JE. Mutational analysis of the Nterminus in Schistocerca gregaria ion-transport peptide expressed in Drosophila Kcl cells. Arch Insect Biochem Physiol (2005) 58:27-38.

89. Katayama H, Ohira T, Nagata S, Nagasawa H. Structure-activity relationship of crustacean molt-inhibiting hormone from the kuruma prawn Marsupenaeus japonicus. Biochemistry (2004) 43:9629-35.

90. Wang YJ, Zhao Y, Meredith J, Phillips JE, Theilmann DA, Brock HW. Mutational analysis of the C-terminus in ion transport peptide (ITP) expressed in Drosophila Kcl cells. Arch Insect Biochem Physiol (2000) 45:129-38.

91. Tsutsui N, Sakamoto T, Arisaka F, Tanokura M, Nagasawa H, Nagata K. Crystal structure of a crustacean hyperglycemic hormone $(\mathrm{CHH})$ precursor suggests structural variety in the C-terminal regions of $\mathrm{CHH}$ superfamily members. FEBS J (2016) 283:4325-39.

92. Katayama H, Nagata K, Ohira T, Yumoto F, Tanokura M, Nagasawa H. The solution structure of molt-inhibiting hormone from the Kuruma prawn Marsupenaeus japonicus. J Biol Chem (2003) 278:9620-3.

93. Chen SH. Structural and functional studies of crustacean hyperglycemic hormone-like (CHH-L) peptide from mud crab Scylla olivacea. Doctoral dissertation. Taiwan: National Tsing Hua University (2017). 112 pp.

94. Nagai C, Mabashi-Asazuma H, Nagasawa H, Nagata S. Identification and characterization of receptors for ion transport peptide (ITP) and ITP-like (ITPL) in the silkworm Bombyx mori. J Biol Chem (2014) 289:32166-77.

95. Tran NM, Mykles DL, Elizur A, Ventura T. Characterization of G-protein coupled receptors from the blackback land crab Gecarcinus lateralis Y organ transcriptome over the molt cycle. BMC Genomics (2019) 20:74.

96. Buckley SJ, Fitzgibbon QP, Smith GG, Ventura T. In silico prediction of the G-protein coupled receptors expressed during the metamorphic molt of Sagmariasus verreauxi (Crustacea: Decapoda) by mining transcriptomic data: RNA-seq to repertoire. Gen Comp Endocrinol (2016) 228:111-27.

97. Veenstra JA. The power of next-generation sequencing as illustrated by the neuropeptidome of the crayfish Procambarus clarkii. Gen Comp Endocrinol (2015) 224:84-95.

98. Chung JS, Zmora N, Katayama H, Tsutsui N. Crustacean hyperglycemic hormone $(\mathrm{CHH})$ neuropeptides family: Functions, titer, and binding to target tissues. Gen Comp Endocrinol (2010) 166:447-54.

99. Gasparini S, Kiyatkin N, Drevet P, Boulain JC, Tacnet F, Ripoche P, et al. The low molecular weight protein which co-purifies with alpha-latrotoxin is structurally related to crustacean hyperglycemic hormones. J Biol Chem (1994) 269:19803-9.

100. Stockmann R, Laverdure AM, Breuzet M. Localization of a crustacean hyperglycemic hormone-like immunoreactivity in the neuroendocrine system of Euscorpius carpathicus (L.) (Scorpionida. Chactidae) Gen Comp Endocrinol (1997) 106:320-6.

101. Egekwu N, Sonenshine DE, Bissinger BW, Roe RM. Transcriptome of the female synganglion of the black-legged tick Ixodes scapularis (Acari: Ixodidae) with comparison between Illumina and 454 systems. PloS One (2014) 9:e102667.

102. Jones SJ, Riddle DL, Pouzyrev AT, Velculescu VE, Hillier L, Eddy SR, et al. Changes in gene expression associated with developmental arrest and longevity in Caenorhabditis elegans. Genome Res (2001) 11:1346-52.

103. Christie AE, McCoole MD, Harmon SM, Baer KN, Lenz PH. Genomic analyses of the Daphnia pulex peptidome. Gen Comp Endocrinol (2011) 171:131-50.

104. Dircksen H, Neupert S, Predel R, Verleyen P, Huybrechts J, Strauss J, et al. Genomics, transcriptomics, and peptidomics of Daphnia pulex neuropeptides and protein hormones. J Proteome Res (2011) 10:4478-504.

105. Kim BM, Jeong CB, Han J, Kim IC, Rhee JS, Lee JS. Role of crustacean hyperglycemic hormone $(\mathrm{CHH})$ in the environmental stressor-exposed intertidal copepod Tigriopus japonicus. Comp Biochem Physiol C Toxicol Pharmacol (2013) 158:131-41.

106. Christie AE. Prediction of the peptidomes of Tigriopus californicus and Lepeophtheirus salmonis (Copepoda. Crustacea) Gen Comp Endocrinol (2014) 201:87-106.
107. Christie AE. Neuropeptide discovery in Eucyclops serrulatus (Crustacea, Copepoda): in silico prediction of the first peptidome for a member of the Cyclopoida. Gen Comp Endocrinol (2015) 211:92-105.

108. Christie AE. Prediction of the first neuropeptides from a member of the Remipedia (Arthropoda, Crustacea). Gen Comp Endocrinol (2014) 201:74-86.

109. Manfrin C, Tom M, De Moro G, Gerdol M, Giulianini PG, Pallavicini A. The eyestalk transcriptome of red swamp crayfish Procambarus clarkii. Gene (2015) 557:28-34.

110. Bao C, Liu F, Yang Y, Lin Q, Ye H. Identification of peptides and their GPCRs in the peppermint shrimp Lysmata vittata, a protandric simultaneous hermaphrodite species. Front Endocrinol (2020) 11:226.

111. Chen HY, Watson RD, Chen JC, Liu HF, Lee CY. Molecular characterization and gene expression pattern of two putative molt-inhibiting hormones from Litopenaeus vannamei. Gen Comp Endocrinol (2007) 151:72-81.

112. Jia C, Hui L, Cao W, Lietz CB, Jiang X, Chen R, et al. High-definition de novo sequencing of crustacean hyperglycemic hormone $(\mathrm{CHH})$-family neuropeptides. Mol Cel Proteomics (2012) 11:1951-64.

113. Toullec JY, Corre E, Bernay B, Thorne MA, Cascella K, Ollivaux C, et al. Transcriptome and peptidome characterisation of the main neuropeptides and peptidic hormones of a euphausiid: the Ice Krill, Euphausia crystallorophias. PloS One (2013) 8:e71609.

114. Luo X, Chen T, Zhong M, Jiang X, Zhang L, Ren C, et al. Differential regulation of hepatopancreatic vitellogenin (VTG) gene expression by two putative molt-inhibiting hormones (MIH1/2) in Pacific white shrimp (Litopenaeus vannamei). Peptides (2015) 68:58-63.

115. Christie AE. Expansion of the neuropeptidome of the globally invasive marine crab Carcinus maenas. Gen Comp Endocrinol (2016) 235:150-69.

116. Krungkasem C, Ohira T, Yang WJ, Abdullah R, Nagasawa H, Aida K. Identification of two distinct molt-inhibiting hormone-related peptides from the giant tiger prawn. Penaeus monodonMar Biotechnol (NY) (2002) 4:13240.

117. Christie AE, Roncalli V, Cieslak MC, Pascual MG, Yu A, Lameyer TJ, et al. Prediction of a neuropeptidome for the eyestalk ganglia of the lobster Homarus americanus using a tissue-specific de novo assembled transcriptome. Gen Comp Endocrinol (2016) 243:96-119.

118. Lu W, Wainwright G, Webster SG, Rees HH, Turner PC. Clustering of mandibular organ-inhibiting hormone and moult-inhibiting hormone genes in the crab, Cancer pagurus, and implications for regulation of expression. Gene (2000) 253:197-207.

119. Oliphant A, Alexander JL, Swain MT, Webster SG, Wilcockson DC. Transcriptomic analysis of crustacean neuropeptide signaling during the moult cycle in the green shore crab, Carcinus maenas. BMC Genomics (2018) 19:711.

120. Jeon JM, Kim BK, Lee JH, Kim HJ, Kang CK, Mykles DL, et al. Two type I crustacean hyperglycemic hormone (CHH) genes in Morotoge shrimp (Pandalopsis japonica): Cloning and expression of eyestalk and pericardial organ isoforms produced by alternative splicing and a novel type I CHH with predicted structure shared with type II CHH peptides. Comp Biochem Physiol B-Biochem Mol Biol (2012) 162:88-99.

121. Das S, Vraspir L, Zhou W, Durica DS, Mykles DL. Transcriptomic analysis of differentially expressed genes in the molting gland (Y-organ) of the blackback land crab, Gecarcinus lateralis, during molt-cycle stage transitions. Comp Biochem Physiol Part D Genomics Proteomics (2018) 28:37-53.

122. Gu PL, Yu KL, Chan SM. Molecular characterization of an additional shrimp hyperglycemic hormone: cDNA cloning, gene organization, expression and biological assay of recombinant proteins. FEBS Lett (2000) 472:122-8.

123. Gu PL, Chan SM. Cloning of a cDNA encoding a putative molt-inhibiting hormone from the eyestalk of the sand shrimp. Metapenaeus ensisMol Mar Biol Biotechnol (1998) 7:214-20.

124. Webster SG, Dircksen H, Chung JS. Endocrine cells in the gut of the shore crab Carcinus maenas immunoreactive to crustacean hyperglycaemic hormone and its precursor-related peptide. Cell Tissue Res (2000) 300:193-205.

125. Ventura-Lopez C, Gomez-Anduro G, Arcos FG, Llera-Herrera R, Racotta IS, Ibarra AM. A novel CHH gene from the Pacific white shrimp Litopenaeus vannamei was characterized and found highly expressed in gut and less in eyestalk and other extra-eyestalk tissues. Gene (2016) 582:148-60. 
126. Fanjul-Moles ML, Escamilla-Chimal EG, Salceda R, Giulianini PG, SánchezChávez G. Circadian modulation of crustacean hyperglycemic hormone in crayfish eyestalk and retina. Chronobiol Int (2010) 27:34-51.

127. Tiu SH, He JG, Chan SM. The LvCHH-ITP gene of the shrimp (Litopenaeus vannamei) produces a widely expressed putative ion transport peptide (LvITP) for osmo-regulation. Gene (2007) 396:226-35.

128. Li SH, Li FH, Wang B, Xie YS, Wen R, Xiang JH. Cloning and expression profiles of two isoforms of a CHH-like gene specifically expressed in male Chinese shrimp, Fenneropenaeus chinensis. Gen Comp Endocrinol (2010) 167:308-16.

129. Xie X, Zhu D, Yang J, Qiu X, Cui X, Tang J. Molecular cloning of two structure variants of crustacean hyperglycemic hormone $(\mathrm{CHH})$ from the swimming crab (Portunus trituberculatus), and their gene expression during molting and ovarian development. Zoolog Sci (2014) 31:802-9.

130. Liu A, Liu J, Chen X, Lu B, Zeng C, Ye H. A novel crustacean hyperglycemic hormone $(\mathrm{CHH})$ from the mud crab Scylla paramamosain regulating carbohydrate metabolism. Comp Biochem Physiol A Mol Integr Physiol (2019) 231:49-55.

131. Zuo H, Yuan J, Niu S, Yang L, Weng S, He J, et al. A molting-inhibiting hormone-like protein from Pacific white shrimp Litopenaeus vannamei is involved in immune responses. Fish Shellfish Immunol (2018) 72:544-51.

132. Qiao H, Jiang F, Xiong Y, Jiang S, Fu H, Li F, et al. Characterization, expression patterns of molt-inhibiting hormone gene of Macrobrachium nipponense and its roles in molting and growth. PloS One (2018) 13: e0198861.

133. Mosco A, Zlatev V, Guarnaccia C, Pongor S, Campanella A, Zahariev S, et al. Novel protocol for the chemical synthesis of crustacean hyperglycemic hormone analogues - an efficient experimental tool for studying their functions. PloS One (2012) 7:e30052.

134. Ollivaux C, Vinh J, Soyez D, Toullec JY. Crustacean hyperglycemic and vitellogenesis-inhibiting hormones in the lobster Homarus gammarus. FEBS $J$ (2006) 273:2151-60.

135. Ollivaux C, Gallois D, Amiche M, Boscameric M, Soyez D. Molecular and cellular specificity of post-translational aminoacyl isomerization in the crustacean hyperglycaemic hormone family. FEBS J (2009) 276:4790-802.

136. Soyez D, Toullec JY, Ollivaux C, Geraud G. L to D amino acid isomerization in a peptide hormone is a late post-translational event occurring in specialized neurosecretory cells. J Biol Chem (2000) 275:37870-5.

137. Ollivaux C, Soyez D. Dynamics of biosynthesis and release of crustacean hyperglycemic hormone isoforms in the X-organ-sinus gland complex of the crayfish Orconectes limosus. Eur J Biochem (2000) 267:5106-14.

138. Gallois D, Brisorgueil MJ, Conrath M, Mailly P, Soyez D. Posttranslational isomerization of a neuropeptide in crustacean neurosecretory cells studied by ultrastructural immunocytochemistry. Europ J Cell Biol (2003) 82:431-40.

139. Katayama H, Ohira T, Aida K, Nagasawa H. Significance of a carboxylterminal amide moiety in the folding and biological activity of crustacean hyperglycemic hormone. Peptides (2002) 23:1537-46.

140. Mosco A, Edomi P, Guarnaccia C, Lorenzon S, Pongor S, Ferrero EA, et al. Functional aspects of cHH C-terminal amidation in crayfish species. Regul Pept (2008) 147:88-95.

141. Wang YJ, Hayes TK, Holman GM, Chavez AR, Keeley LL. Primary structure of $\mathrm{CHH} / \mathrm{MIH} / \mathrm{GIH}$-like peptides in sinus gland extracts from Penaeus vannamei. Peptides (2000) 21:477-84.

142. Marco HG, Stoeva S, Voelter W, Gade G. Characterization and sequence elucidation of a novel peptide with molt-inhibiting activity from the South African spiny lobster, Jasus lalandii. Peptides (2000) 21:1313-21.

143. Nagasawa H, Yang WJ, Shimizu H, Aida K, Tsutsumi H, Terauchi A, et al. Isolation and amino acid sequence of a molt-inhibiting hormone from the American crayfish, Procambarus clarkii. Biosci Biotechnol Biochem (1996) 60:554-6.

144. Chung JS, Webster SG. Does the N-terminal pyroglutamate residue have any physiological significance for crab hyperglycemic neuropeptides? Eur J Biochem (1996) 240:358-64.

145. Bai L, Sheeley S, Sweedler JV. Analysis of endogenous D-amino acidcontaining peptides in Metazoa. Bioanal Rev (2009) 1:7-24.

146. Kreil G. D-amino acids in animal peptides. Annu Rev Biochem (1997) $66: 337-45$.
147. Soyez D. Occurrence and diversity of neuropeptides from the crustacean hyperglycemic hormone family in arthropods - A short review. Ann Ny Acad Sci Neuropeptides Dev Aging (1997) 814:319-23.

148. Johnson JH, Bloomquist JR, Krapcho KJ, Kral, Jr. RM, Trovato R, Eppler KG, et al. Novel insecticidal peptides from Tegenaria agrestis spider venom may have a direct effect on the insect central nervous system. Arch Insect Biochem Physiol (1998) 38:19-31.

149. King GF, Hardy MC. Spider-venom peptides: structure, pharmacology, and potential for control of insect pests. Annu Rev Entomol (2013) 58:475-96.

150. Liu NY, Xu ZW, Yan W, Ren XM, Zhang ZQ, Zhu JY. Venomics reveals novel ion transport peptide-likes (ITPLs) from the parasitoid wasp Tetrastichus brontispae. Toxicon (2018) 141:88-93.

151. Audsley N, McIntosh C, Phillips JE. Purification of a new neuropeptide from locust corpus cardiacum which influences ileal transport. Prog Brain Res (1992) 92:157-62.

152. Keller R. Purification and amino-acid composition of the hyperglycemic neurohormone from the sinus gland of Orconectes limosus and comparison with the hormone from Carcinus maenas. J Comp Physiol (1981) 141:445-50.

153. Abramowitz AA, Hisaw FL, Papandrea DN. The occurrence of a diabetogenic factor in the eyestalks of crustaceans. Biol Bul (1944) 86:1-5.

154. Parvathy D. Endocrine regulation of carbohydrate metabolism during the moult cycle in crustaceans I. Effect of eyestalk removal in Ocypoda platytarsis. Mar Biol (1972) 14:58.

155. Sedlmeier D. The role of hepatopancreatic glycogen in the action of the crustacean hyperglycemic hormone (CHH). Comp Biochem Physiol (1987) $87: 423-5$.

156. Sedlmeier D, Keller R. The mode of action of the crustacean neurosecretory hyperglycemic hormone. I Involvement cyclic nucleotides. Gen Comp Endocrinol (1981) 45:82-90.

157. Sedlmeier D. The mode of action of the crustacean neurosecretory hyperglycemic hormone $(\mathrm{CHH})$. II Involvement glycogen synthase Gen Comp Endocrinol (1982) 47:426-32.

158. Keller R, Andrew EM. The site of action of the crustacean hyperglycemic hormone. Gen Comp Endocrinol (1973) 20:572-8.

159. Nagai C, Nagata S, Nagasawa H. Effects of crustacean hyperglycemic hormone $(\mathrm{CHH})$ on the transcript expression of carbohydrate metabolism-related enzyme genes in the kuruma prawn, Marsupenaeus japonicus. Gen Comp Endocrinol (2011) 172:293-304.

160. Santos EA, Keller R. Crustacean hyperglycemic hormone $(\mathrm{CHH})$ and the regulation of carbohydrate metabolism: current perspectives. Comp Biochem Physiol (1993) 106:405-11.

161. Santos EA, Keller R. Effect of exposure to atmospheric air on blood glucose and lactate concentrations in two crustacean species: A role of the crustacean hyperglycemic hormone (CHH). Comp Biochem Physiol (1993) 106:343-7.

162. Sedlmeier D. The crustacean hyperglycemic hormone $(\mathrm{CHH})$ releases amylase from the crayfish midgut gland. Regul Pept (1988) 20:91-8.

163. Santos EA, Nery LE, Keller R, Goncalves AA. Evidence for the involvement of the crustacean hyperglycemic hormone in the regulation of lipid metabolism. Physiol Zool (1997) 70:415-20.

164. Charmantier-Daures M, Charmantier G, Janssen KP, Aiken DE, van Herp F. Involvement of eyestalk factors in the neuroendocrine control of osmoregulation in adult American lobster Homarus americanus. Gen Comp Endocrinol (1994) 94:281-93.

165. Spanings-Pierrot C, Soyez D, Van Herp F, Gompel M, Skaret G, Grousset E, et al. Involvement of crustacean hyperglycemic hormone in the control of gill ion transport in the crab Pachygrapsus marmoratus. Gen Comp Endocrinol (2000) 119:340-50.

166. Chang ES, Chang SA, Keller R, Reddy PS, Snyder MJ, Spees JL. Quantification of stress in lobsters: Crustacean hyperglycemic hormone, stress proteins and gene expression. Am Zool (1999) 39:487-95.

167. Fingerman M, Hanumante MM, Deshpande UD, Nagabhushanam R. Increase in the total reducing substances in the haemolymph of the freshwater crab, Barytelphusa guerini, produced by a pesticide (DDT) and an indolealkylamine (serotonin). Experientia (1981) 37:178-9.

168. Chang ES, Keller R, Chang SA. Quantification of crustacean hyperglycemic hormone by ELISA in hemolymph of the lobster, Homarus americanus, following various stresses. Gen Comp Endocrinol (1998) 111:359-66. 
169. Reddy PS, Devi M, Sarojini R, Nagabhushanam R, Fingerman M. Cadmium chloride induced hyperglycemia in the red swamp crayfish, Procambarus clarkii: Possible role of crustacean hyperglycemic hormone. Comp Biochem Phys (1994) 107:57-61.

170. Webster S. Measurement of crustacean hyperglycaemic hormone levels in the edible crab Cancer pagurus during emersion stress. J Exp Biol (1996) 199:1579-85.

171. Zou HS, Juan CC, Chen SC, Wang HY, Lee CY. Dopaminergic regulation of crustacean hyperglycemic hormone and glucose levels in the hemolymph of the crayfish. Procambarus clarkiiJ Exp Zoolog A Comp Exp Biol (2003) 298:44-52.

172. Chang CC, Tsai KW, Hsiao NW, Chang CY, Lin CL, Watson RD, et al. Structural and functional comparisons and production of recombinant crustacean hyperglycemic hormone $(\mathrm{CHH})$ and $\mathrm{CHH}$-like peptides from the mud crab Scylla olivacea. Gen Comp Endocrinol (2010) 167:68-76.

173. Ohira T, Tsutsui N, Nagasawa H, Wilder MN. Preparation of two recombinant crustacean hyperglycemic hormones from the giant freshwater prawn, Macrobrachium rosenbergii, and their hyperglycemic activities. Zoolog Sci (2006) 23:383-91.

174. Galikova M, Dircksen H, Nassel DR. The thirsty fly: Ion transport peptide (ITP) is a novel endocrine regulator of water homeostasis in Drosophila. PloS Genet (2018) 14:e1007618.

175. Lorenzon S, Giulianini PG, Ferrero EA. Lipopolysaccharide-induced hyperglycemia is mediated by $\mathrm{CHH}$ release in crustaceans. Gen Comp Endocrinol (1997) 108:395-405.

176. Noch E, Khalili K. Oncogenic viruses and tumor glucose metabolism: like kids in a candy store. Mol Cancer Ther (2012) 11:14-23.

177. Chen IT, Aoki T, Huang YT, Hirono I, Chen TC, Huang JY, et al. White spot syndrome virus induces metabolic changes resembling the warburg effect in shrimp hemocytes in the early stage of infection. J Virol (2011) 85:12919-28.

178. Su MA, Huang YT, Chen IT, Lee DY, Hsieh YC, Li CY, et al. An invertebrate Warburg effect: a shrimp virus achieves successful replication by altering the host metabolome via the PI3K-Akt-mTOR pathway. PloS Pathog (2014) 10: e1004196.

179. Chen Y. Effects of silencing crustacean hyperglycemic hormone gene expression on the proliferation of white spot syndrome virus and survival of virus-infected host (Procambarus clarkii). Master's thesis. Taiwan: National Changhua University of Education (2018). 74 pp.

180. Xu L, Pan L, Zhang X, Wei C. Effects of crustacean hyperglycemic hormone $(\mathrm{CHH})$ on regulation of hemocyte intracellular signaling pathways and phagocytosis in white shrimp. Litopenaeus vannamei.Fish Shellfish Immunol (2019) 93:559-66.

181. Johnston MA, Davies PS. Carbohydrates of the hepatopancreas and blood tissues of Carcinus. Comp Biochem Physiol B (1972) 41:433-43.

182. Johnston MA, Davies PS, Elder HY. Possible function for crustacean blood cells. Nature (1970) 230:471-2.

183. Johnston MA, Davies PS, Elder HY. Cytology of Carcinus haemocytes and their function in carbohydrate metabolism. Comp Biochem Physiol A (1973) 46:569-81.

184. Webster S, Keller R. Purification, characterization and amino acid composition of the putative molt-inhibiting hormone (MIH) of Carcinus maenas (Crustacea. Decapoda) J Comp Physiol (1986) 156:617-24.

185. Chung JS, Webster SG. Moult cycle-related changes in biological activity of moult-inhibiting hormone (MIH) and crustacean hyperglycaemic hormone $(\mathrm{CHH})$ in the crab, Carcinus maenas. From target to transcript. Eur J Biochem (2003) 270:3280-8.

186. Liu L, Laufer H, Wang Y, Hayes T. A neurohormone regulating both methyl farnesoate synthesis and glucose metabolism in a crustacean. Biochem Biophys Res Commun (1997) 237:694-701.

187. Chang ES, Bruce MJ. Ecdysteroid titers of juvenile lobsters following molt induction. J Exp Zool (1980) 214:157-60.

188. Keller R, Schmid E. In vitro secretion of ecdysteroids by Y-organs and lack of secretion by mandibular organs of the crayfish following molt induction. J Comp Physiol (1979) 130:347-53.

189. Mattson MP, Spaziani E. Cyclic AMP mediates the negative regulation of Yorgan ecdysteroid production. Mol Cell Endocrinol (1985) 42:185-9.

190. Okumura T, Ohira T, Katayama H, Nagasawa H. In vivo effects of a recombinant molt-inhibiting hormone on molt interval and hemolymph ecdysteroid level in the kuruma prawn, Marsupenaeus japonicus. Zoolog Sci (2005) 22:317-20.

191. Mattson MP, Spaziani E. Characterization of molt-inhibiting hormone (MIH) action on crustacean Y-organ segments and dispersed cells in culture and a bioassay for MIH activity. J Exp Zool (1985) 236:93-101.

192. Nakatsuji T, Sonobe H, Watson RD. Molt-inhibiting hormone-mediated regulation of ecdysteroid synthesis in Y-organs of the crayfish (Procambarus clarkii): involvement of cyclic GMP and cyclic nucleotide phosphodiesterase. Mol Cell Endocrinol (2006) 253:76-82.

193. Webster S. High-affinity binding of putative moult-inhibiting hormone $(\mathrm{MIH})$ and crustacean hyperglycaemic hormone (CHH) to membranebound receptors on the Y-organ of the shore crab Carcinus maenas. Proc R Soc Lond Ser B Biol Sci (1993) 251:53-9.

194. Zmora N, Sagi A, Zohar Y, Chung JS. Molt-inhibiting hormone stimulates vitellogenesis at advanced ovarian developmental stages in the female blue crab, Callinectes sapidus 2: novel specific binding sites in hepatopancreas and cAMP as a second messenger. Saline Syst (2009) 5:6.

195. Asazuma H, Nagata S, Katayama H, Ohira T, Nagasawa H. Characterization of a molt-inhibiting hormone (MIH) receptor in the Y-organ of the kuruma prawn, Marsupenaeus japonicus. Ann N Y Acad Sci (2005) 1040:215-8.

196. Nakatsuji T, Lee CY, Watson RD. Crustacean molt-inhibiting hormone: structure, function, and cellular mode of action. Comp Biochem Physiol A Mol Integr Physiol (2009) 152:139-48.

197. Nakatsuji T, Keino H, Tamura K, Yoshimura S, Kawakami T, Aimoto S, et al. Changes in the amounts of the molt-inhibiting hormone in sinus glands during the molt cycle of the American crayfish, Procambarus clarkii. Zoolog Sci (2000) 17:1129-36.

198. Techa S, Chung JS. Ecdysteroids regulate the levels of Molt-Inhibiting Hormone (MIH) expression in the blue crab, Callinectes sapidus. PloS One (2015) 10:e0117278.

199. Chung JS, Webster. SG. Dynamics of in vivo release of molt-inhibiting hormone and crustacean hyperglyc6emic hormone in the shore crab, Carcinus maenas. Endocrinology (2005) 146:5545-51.

200. Lee KJ, Watson RD, Roer RD. Molt-inhibiting hormone mRNA levels and ecdysteroid titer during a molt cycle of the blue crab, Callinectes sapidus. Biochem Biophys Res Commun (1998) 249:624-7.

201. Huang H, Fu C, Chen X, Gong J, Huang X, Ye H. Molt-inhibiting hormone (MIH) gene from the green mud crab Scylla paramamosain and its expression during the molting and ovarian cycle. Aquac Res (2015) 46:2665-75.

202. Nakatsuji $\mathrm{T}$, Sonobe $\mathrm{H}$. Regulation of ecdysteroid secretion from the $\mathrm{Y}$-organ by molt-inhibiting hormone in the American crayfish, Procambarus clarkii. Gen Comp Endocrinol (2004) 135:358-64.

203. Pamuru RR, Rosen O, Manor R, Chung JS, Zmora N, Glazer L, et al. Stimulation of molt by RNA interference of the molt-inhibiting hormone in the crayfish Cherax quadricarinatus. Gen Comp Endocrinol (2012) 178:227-36.

204. Liang H, Liu Y, Zhou TT, Li X, Li B, Chan SF. Molecular characterization, RNA interference and recombinant protein approach to study the function of the putative Molt Inhibiting Hormone (FmMIH1) gene from the shrimp Fenneropenaeus merguiensis. Peptides (2019) 122:16985.

205. Lee CY, Umphrey HR, Watson RD. Developmental changes in the level of vitellin-immunoreactive proteins in hemolymph and tissues of the blue crab Callinectes sapidus: relation to vitellogenesis. J Crustacean Biol (1995) 16:1-9.

206. Quackenbush LS. Yolk synthesis in the marine shrimp, Penaeus vannamei. Comp Biochem Physiol (1992) 103:711-4.

207. Sagi A, Soroka Y, Snir E, Chomsky O, Calderon J, Milner Y. Ovarian protein synthesis in the prawn Macrobrachium rosenbergii: Does ovarian vitellin synthesis exist? Invert Reprod Dev (1995) 27:41-7.

208. Okuno A, Yang WJ, Jayasankar V, Saido-Sakanaka H, Huong DT, Jasmani S, et al. Deduced primary structure of vitellogenin in the giant freshwater prawn, Macrobrachium rosenbergii, and yolk processing during ovarian maturation. J Exp Zool (2002) 292:417-29.

209. Warrier S, Subramoniam T. Receptor mediated yolk protein uptake in the crab Scylla serrata: crustacean vitellogenin receptor recognizes related mammalian serum lipoproteins. Mol Reprod Dev (2002) 61:536-48.

210. Thongda W, Chung JS, Tsutsui N, Zmora N, Katenta A. Seasonal variations in reproductive activity of the blue crab, Callinectes sapidus: Vitellogenin expression and levels of vitellogenin in the hemolymph during ovarian development. Comp Biochem Physiol A Mol Integr Physiol (2015) 179:35-43. 
211. Zmora N, Trant J, Zohar Y, Chung JS. Molt-inhibiting hormone stimulates vitellogenesis at advanced ovarian developmental stages in the female blue crab, Callinectes sapidus 1: an ovarian stage dependent involvement. Saline Syst (2009) 5:7.

212. Tiu SH, Chan SM. The use of recombinant protein and RNA interference approaches to study the reproductive functions of a gonad-stimulating hormone from the shrimp Metapenaeus ensis. FEBS J (2007) 274:4385-95.

213. Yang WJ, Rao KR. Cloning of precursors for two MIH/VIH-related peptides in the prawn, Macrobrachium rosenbergii. Biochem Biophys Res Commun (2001) 289:407-13.

214. Edomi P, Azzoni E, Mettulio R, Pandolfelli N, Ferrero EA, Giulianini PG. Gonad-inhibiting hormone of the Norway lobster (Nephrops norvegicus): cDNA cloning, expression, recombinant protein production, and immunolocalization. Gene (2002) 284:93-102.

215. Treerattrakool S, Panyim S, Chan SM, Withyachumnarnkul B, Udomkit A. Molecular characterization of gonad-inhibiting hormone of Penaeus monodon and elucidation of its inhibitory role in vitellogenin expression by RNA interference. FEBS J (2008) 275:970-80.

216. Chen T, Zhang LP, Wong NK, Zhong M, Ren CH, Hu CQ. Pacific white shrimp (Litopenaeus vannamei) vitellogenesis-inhibiting hormone (VIH) is predominantly expressed in the brain and negatively regulates hepatopancreatic vitellogenin (VTG) gene expression. Biol Reprod (2014) 90:47.

217. Treerattrakool S, Panyim S, Udomkit A. Induction of ovarian maturation and spawning in Penaeus monodon broodstock by double-stranded RNA. Mar Biotechnol (NY) (2011) 13:163-9.

218. Homola E, Chang ES. Methyl farnesoate: Crustacean juvenile hormone in search of function. Comp Biochem Physiol Biochem Mol Biol (1997) 117:34756.

219. Borst DW, Ogan J, Tsukimura B, Claerhout T, Holford KC. Regulation of the Crustacean Mandibular Organ. Amer Zool (2001) 41:430-41.

220. Laufer H, Borst D, Baker FC, Reuter CC, Tsai LW, Schooley DA, et al. Identification of a juvenile hormone-like compound in a crustacean. Science (1987) 235:202-5.

221. Laufer H, Biggers WJ, Ahl JS. Stimulation of ovarian maturation in the crayfish Procambarus clarkii by methyl farnesoate. Gen Comp Endocrinol (1998) 111:113-8.

222. Laufer H, Demir N, Pan X, Stuart JD, Ahl JS. Methyl farnesoate controls adult male morphogenesis in the crayfish, Procambarus clarkii. $J$ Insect Physiol (2005) 51:379-84.

223. Borst DW, Tsukimura B. Method for measuring hemolymph levels of methyl farnesoate by HPLC. J Chromatogr (1991) 545:71-8.

224. Tsukimura B, Borst DW. Regulation of methyl farnesoate levels in the lobster, Homarus americanus. Gen Comp Endocrinol (1992) 86:287-303.

225. Tang C, Lu W, Wainwright G, Webster SG, Rees HH, Turner PC. Molecular characterization and expression of mandibular organ-inhibiting hormone, a recently discovered neuropeptide involved in the regulation of growth and reproduction in the crab Cancer pagurus. Biochem J (1999) 343 Pt 2:355-60.

226. Webster SG. "Neuropeptides inhibiting growth and reproduction in crustaceans". In: GM Coast and SG Webster, editors. Recent advances in arthropod endocrinology. Cambridge: Cambridge University Press (1998). p. 33-52.

227. Katayama $H$, Nagasawa $H$. Effect of a glycine residue insertion into crustacean hyperglycemic hormone on hormonal activity. Zoolog Sci (2004) 21:1121-4

228. Kummer G, Keller R. High-affinity binding of crustacean hyperglycemic hormone $(\mathrm{CHH})$ to hepatopancreatic plasma membranes of the crab Carcinus maenas and the crayfish Orconectes limosus. Peptides (1993) 14:103-8.

229. Katayama H, Chung JS. The specific binding sites of eyestalk- and pericardial organ-crustacean hyperglycaemic hormones (CHHs) in multiple tissues of the blue crab, Callinectes sapidus. J Exp Biol (2009) 212:542-9.

230. Chang ES, Mykles DL. Regulation of crustacean molting: a review and our perspectives. Gen Comp Endocrinol (2011) 172:323-30.

231. Nagai C, Asazuma H, Nagata S, Nagasawa H. Identification of a second messenger of crustacean hyperglycemic hormone signaling pathway in the kuruma prawn Marsupenaeus japonicus. Ann Ny Acad Sci Trends Comp Endocrinol Neurobiol (2009) 1163:478-80.
232. Goy MF, Mandelbrot DA, York CM. Identification and characterization of a polypeptide from a lobster neurosecretory gland that induces cyclic GMP accumulation in lobster neuromuscular preparations. J Neurochem (1987) 48:954-66.

233. Goy MF. Activation of membrane guanylate cyclase by an invertebrate peptide hormone. J Biol Chem (1990) 265:20220-7.

234. Liu HF, Lai CY, Watson RD, Lee CY. Molecular cloning of a putative membrane form guanylyl cyclase from the crayfish Procambarus clarkii. J Exp Zoolog A Comp Exp Biol (2004) 301:512-20.

235. Sedlmeier D, Fenrich R. Regulation of ecdysteroid biosynthesis in crayfish $Y$ organs: I. Role of cyclic nucleotides. J Exp Zool (1993) 265:448-53.

236. Nakatsuji T, Han DW, Jablonsky MJ, Harville SR, Muccio DD, Watson RD. Expression of crustacean (Callinectes sapidus) molt-inhibiting hormone in Escherichia coli: characterization of the recombinant peptide and assessment of its effects on cellular signaling pathways in Y-organs. Mol Cell Endocrinol (2006) 253:96-104.

237. Saidi B, de Besse N, Webster SG, Sedlmeier D, Lachaise F. Involvement of cAMP and cGMP in the mode of action of molt-inhibiting hormone (MIH) a neuropeptide which inhibits steroidogenesis in a crab. Mol Cell Endocrinol (1994) 102:53-61.

238. Zheng J, Lee CY, Watson RD. Molecular cloning of a putative receptor guanylyl cyclase from Y-organs of the blue crab, Callinectes sapidus. Gen Comp Endocrinol (2006) 146:329-36.

239. Zheng J, Nakatsuji T, Roer RD, Watson RD. Studies of a receptor guanylyl cyclase cloned from Y-organs of the blue crab (Callinectes sapidus), and its possible functional link to ecdysteroidogenesis. Gen Comp Endocrinol (2008) 155:780-8.

240. Lee SG, Bader BD, Chang ES, Mykles DL. Effects of elevated ecdysteroid on tissue expression of three guanylyl cyclases in the tropical land crab Gecarcinus lateralis: possible roles of neuropeptide signaling in the molting gland. J Exp Biol (2007) 210:3245-54.

241. Lee SG, Mykles DL. Proteomics and signal transduction in the crustacean molting gland. Integr Comp Biol (2006) 46:965-77.

242. Kim HW, Batista LA, Hoppes JL, Lee KJ, Mykles DL. A crustacean nitric oxide synthase expressed in nerve ganglia, Y-organ, gill and gonad of the tropical land crab, Gecarcinus lateralis. J Exp Biol (2004) 207:2845-57.

243. Lee SG, Kim HW, Mykles DL. Guanylyl cyclases in the tropical land crab, Gecarcinus lateralis: cloning of soluble (NO-sensitive and -insensitive) and membrane receptor forms. Comp Biochem Physiol (2007) 2D:332-44.

244. Das S, Pitts NL, Mudron MR, Durica DS, Mykles DL. Transcriptome analysis of the molting gland (Y-organ) from the blackback land crab, Gecarcinus lateralis. Comp Biochem Physiol Part D Genomics Proteomics (2016) 17:2640.

245. Mykles DL, Chang ES. Hormonal control of the crustacean molting gland: Insights from transcriptomics and proteomics. Gen Comp Endocrinol (2020) 294:113493.

246. Das S, Mykles DL. A Comparison of resources for the annotation of a de novo assembled transcriptome in the molting gland (Y-Organ) of the blackback land crab, Gecarcinus lateralis. Integr Comp Biol (2016) 56:1103-12.

247. Mykles DL, Ghalambor CK, Stillman JH, Tomanek L. Grand challenges in comparative physiology: integration across disciplines and across levels of biological organization. Integr Comp Biol (2010) 50:6-16.

248. Covi JA, Chang ES, Mykles DL. Conserved role of cyclic nucleotides in the regulation of ecdysteroidogenesis by the crustacean molting gland. Comp Biochem Physiol A (2009) 152:470-7.

249. Okumura T. Effects of cyclic nucleotides, calcium ionophore, and phorbol ester on vitellogenin mRNA levels in incubated ovarian fragments of the kuruma prawn Marsupenaeus japonicus. Gen Comp Endocrinol (2006) 148:245-51.

250. Chen T, Ren C, Jiang X, Zhang L, Li H, Huang W, et al. Mechanisms for type-II vitellogenesis-inhibiting hormone suppression of vitellogenin transcription in shrimp hepatopancreas: Crosstalk of GC/cGMP pathway with different MAPK-dependent cascades. PloS One (2018) 13:e0194459.

251. Wainwright G, Webster SG, Rees HH. Involvement of adenosine cyclic-3',5'monophosphate in the signal transduction pathway of mandibular organinhibiting hormone of the edible crab, Cancer pagurus. Mol Cell Endocrinol (1999) 154:55-62. 
252. Audsley N, Jensen D, Schooley DA. Signal transduction for Schistocerca gregaria ion transport peptide is mediated via both cyclic AMP and cyclic GMP. Peptides (2013) 41:74-80.

253. von Reumont BM, Blanke A, Richter S, Alvarez F, Bleidorn C, Jenner RA. The first venomous crustacean revealed by transcriptomics and functional morphology: remipede venom glands express a unique toxin cocktail dominated by enzymes and a neurotoxin. Mol Biol Evol (2014) 31:48-58.

254. Sonobe H, Nishimura T, Sonobe M, Nakatsuji T, Yanagihara R, Kawakami T, et al. The molt-inhibiting hormone in the American crayfish Procambarus clarkii: its chemical synthesis and biological activity. Gen Comp Endocrinol (2001) 121:196-204.

255. Treerattrakool S, Udomkit A, Eurwilaichitr L, Sonthayanon B, Panyim S. Expression of biologically active crustacean hyperglycemic hormone $(\mathrm{CHH})$ of Penaeus monodon in Pichia pastoris. Mar Biotechnol (NY) (2003) 5:373-9.
256. Rosen O, Manor R, Weil S, Aflalo ED, Bakhrat A, Abdu U, et al. An androgenic gland membrane-anchored gene associated with the crustacean insulin-like androgenic gland hormone. J Exp Biol (2013) 216:2122-8.

Conflict of Interest: The authors declare that the research was conducted in the absence of any commercial or financial relationships that could be construed as a potential conflict of interest.

Copyright (c) 2020 Chen, Toullec and Lee. This is an open-access article distributed under the terms of the Creative Commons Attribution License (CC BY). The use, distribution or reproduction in other forums is permitted, provided the original author(s) and the copyright owner(s) are credited and that the original publication in this journal is cited, in accordance with accepted academic practice. No use, distribution or reproduction is permitted which does not comply with these terms. 